\title{
A space-vector modulation scheme for a dual two-level inverter fed open-end winding induction motor drive for the elimination of zero-sequence currents
}

\author{
V.T.Somasekhar, K.Gopakumar, E.G.Shivakumar
}

Key words: _Space-vector modulation, dual-inverter drives, zero sequence currents.

\begin{abstract}
:
The dual two-level inverter fed open-end winding induction motor drive gives voltage space phasor locations similar to a three- level inverter fed induction motor drive. The dual inverter scheme renders advantages such as redundancy of the space vector combinations for the same number of space vector locations and the absence of neutral point fluctuations. In a dual-inverter scheme, a total of 64 space-vector combinations are distributed over 19 space vector locations compared to 27 space-vector combinations distributed over the same number of locations in a three-level inverter. The common mode voltages (the harmonics of the triplen order) need to be suppressed by transformer isolation or the use of harmonic filters. In this paper, a space vector modulation scheme for the suppression of zero sequence currents (the harmonics of the triplen order) for a dual two-level inverter fed open-end winding induction motor drive is described. The proposed scheme does not require bulky transformers or harmonic filters for the elimination of the zero sequence currents. The proposed space vector PWM is based on the observation that certain voltage space-vector combinations in the dual inverter scheme do not contribute to the triplen harmonics and hence the PWM scheme that exclusively employs these combinations is used to eliminate the triplen harmonic currents.
\end{abstract}

\section{Introduction}

The dual two-level inverter fed open-end winding induction motor drives offer certain advantages compared to the three-level inverter drives such as - redundancy of the space vector combinations for the same number of space vector locations and the absence of neutral point fluctuations. A dual- inverter fed open-end winding induction motor drive using sine-triangle PWM scheme has been suggested by H. Stemmler and P. Guggenbach [1]. In this work two two-level inverters are used to feed the opposite ends of the open-end winding induction motor, employing phase-shifted sine-triangle PWM. E.G.Shivakumar et al. have suggested a space-vector based PWM scheme for the dual-inverter driven open-end winding induction motor drive [3]. In this scheme [3], the common mode voltages (the harmonics of the triplen order) in the phase of the motor were suppressed by employing an isolated DC-power supply for each inverter. Thus, this scheme requires two isolation transformers for realizing two isolated DC-power supplies.

In this paper, an alternative PWM scheme is suggested which is based on the space-vector modulation. This PWM scheme eliminates the need for the isolation transformers, thus saving a substantial cost. The proposed space vector PWM is based on the observation that certain voltage space-vector combinations in the dual inverter scheme do not contribute to the triplen harmonics and hence the PWM scheme that exclusively employs these combinations achieves the elimination of the triplen harmonic currents.

\section{Dual inverter fed induction motor with open-end winding}

The schematic of the dual two-level inverter fed three-phase induction motor with open-end winding is shown in Fig.1. The pole voltages of inverter- 1 are denoted as $-\mathrm{V}_{\mathrm{ao}}, \mathrm{v}_{\mathrm{bo}}, \mathrm{v}_{\mathrm{co}}$ while $\mathrm{V}_{\mathrm{a}}$ 'o, $\mathrm{v}_{\mathrm{b}}$ 'o, $\mathrm{v}_{\mathrm{c}}$ 'o denote the pole voltages of inverter-2. The space-vector locations from individual inverters are shown in Fig.2 and each inverter is capable of assuming 8-states independently of the other. Hence the dual-inverter scheme exhibits a total of 64 space-vector combinations from the two inverters as shown in Fig.3. In Fig.3, $|\mathrm{OA}|$ represents the DC-link voltage of individual inverters, and is equal to $\mathrm{V}_{\mathrm{dc}} / 2$ while $|\mathrm{OG}|$ represents the voltage of an equivalent single inverter drive, and is equal to $\mathrm{V}_{\mathrm{dc}}$. For the primitive scheme shown in Fig.1, a significant triplen harmonic content in the inverter phase currents is expected because of the lack of an isolated neutral point. Different space phasor combinations will have different third harmonic voltage magnitudes. This fact may be verified by assuming a particular space phasor combination for the dual inverter scheme [3]. For example, a combination 6-1' implies that the switching state for inverter-1 is (+ + ) and that for inverter-2 is (+ - -). A ' +' indicates that a top switch in an inverter leg is turned on and a '-' indicates 
that the bottom switch in an inverter leg is turned on. The motor phase voltage can be found out from the pole voltages from individual inverters. For example, for the combination 6-1', recognizing that the pole voltages for each inverter are half the DC bus voltages for the individual inverters are:

The motor phase voltage $v_{a a^{\prime}}=v_{a o}-v_{a^{\prime} o}=V_{d c} / 4-V_{d c} / 4=0$

The motor phase voltage $v_{b b^{\prime}}=v_{b o}-v_{b^{\prime} o}=-V_{d c} / 4-\left(-V_{d c} / 4\right)=0$

The motor phase voltage $v_{c c^{\prime}}=v_{c o}-v_{c^{\prime} o}=V_{d c} / 4-\left(-V_{d c} / 4\right)=V_{d c} / 2$

The zero-sequence (harmonic content of triplen order) voltage is given by:

$v_{Z S}=(1 / 3) *\left(v_{a a^{\prime}}+v_{b b^{\prime}}+v_{C C^{\prime}}\right)$

For the combination 6-1', the zero-sequence content of the phase voltage is:

$v_{Z S}\left(6-1^{\prime}\right)=(1 / 3) *\left(v_{a a^{\prime}}+v_{b b^{\prime}}+v_{C c^{\prime}}\right)=V_{d c} / 6$

Since the triplen harmonic voltages are in phase, the sum of the phase voltages not being equal to zero implies the presence of triplen harmonic content. Hence for the combination 6-1' the net triplen harmonic voltage from all the three phases is equal to $\mathrm{V}_{\mathrm{dc}} / 6$. The triplen harmonic contribution from different space phasor combinations is shown in Table-1 [1], [3].

Table-1: Third harmonic contributions from various combinations

\begin{tabular}{|c|c|c|c|c|c|c|c|c|c|}
\hline$-V_{\mathrm{dc}} / 2$ & $-V_{d c} / 3$ & $-V_{d c} / 6$ & \multicolumn{3}{|l|}{$\mathbf{0}$} & \multicolumn{2}{|c|}{$\mathrm{V}_{\mathrm{dc}} / 6$} & $\mathbf{V}_{\mathrm{dc}} / 3$ & $\mathbf{V}_{\mathrm{dc}} / \mathbf{2}$ \\
\hline \multirow[t]{8}{*}{$8-7$} & $8-4^{\prime}$ & $8-5^{\prime} \quad 8-3^{\prime}$ & $8-8$ & $5-5^{\prime}$ & $5-3^{\prime}$ & $5-8$ & $3-8$ & $4-8^{\prime}$ & $7-8^{\prime}$ \\
\hline & $8-6$ & $5-4^{\prime} \quad 3-4^{\prime}$ & $3-5$ & $3-3^{\prime}$ & $4-4 \prime$ & $4-5$ & $4-3^{\prime}$ & $6-8^{\prime}$ & \\
\hline & $8-2^{\prime}$ & $8-1^{\prime} \quad 5-6^{\prime}$ & $5-1$ & $3-1^{\prime}$ & $4-6^{\prime}$ & $4-1$ & $1-8^{\prime}$ & $2-8^{\prime}$ & \\
\hline & $5-7^{\prime}$ & $5-2^{\prime} \quad 3-6^{\prime}$ & $4-2$ & $1-5^{\prime}$ & $1-3^{\prime}$ & $6-5$ & $6-3^{\prime}$ & $7-5^{\prime}$ & \\
\hline & $3-7$ & $3-2^{\prime} \quad 4-7^{\prime}$ & $6-4^{\prime}$ & $2-4$ & $1-1^{\prime}$ & $2-5$ & $2-3^{\prime}$ & $7-3^{\prime}$ & \\
\hline & $1-7^{\prime}$ & $1-4^{\prime} \quad 1-6^{\prime}$ & $6-6^{3}$ & $6-2^{\prime}$ & $2-6^{\prime}$ & $7-4$ & $6-1^{\prime}$ & $7-1^{\prime}$ & \\
\hline & & $1-2^{\prime} \quad 6-7^{\prime}$ & $2-2$ & $7-7^{\prime}$ & & $2-1$ & $7-6^{\prime}$ & & \\
\hline & & $2-7$ & & & & $7-2$ & & & \\
\hline
\end{tabular}

There are twenty space phasor combinations with a third harmonic contribution of zero (Table-1). But if these space phasor combinations are exclusively used, the magnitude of the fundamental component in the output gets reduced (Fig.4). However, by giving an additional boost to the DC-link voltage it is possible to obtain the rated phase voltage of the motor from the dual inverter configuration. The required value for the DC-link voltage may be obtained by the determination of the maximum phase voltage that can be obtained from the voltage space phasor with a length equal to the radius of the circle inscribed in the hexagon HJLNQS (Fig.4).

From Fig. 4:

$|\mathbf{O G}|=V_{d c}$

where $\mathrm{V}_{\mathrm{dc}}$ is the DC-link voltage of the equivalent conventional two-level inverter.

The radius of the largest inscribed circle, OT (Fig.4), gives the length of the voltage space phasor at the boundary of linear modulation: 


$$
\mathbf{O T}=\sqrt{3} / 2 *|\mathbf{O H}|=(\sqrt{3} / 2) *(\sqrt{3} / 2) * V_{d c}=3 / 4 * V_{d c}
$$

Hence the maximum value of the phase voltage that may be obtained from the dual inverter configuration is given by :

$$
v_{\text {ph, peak }}=(2 / 3) *(3 / 4) * V_{d c}=V_{d c} / 2
$$

In the above expression the factor (2/3) arises from the conventional $\alpha-\beta$ to a-b-c transformation:

$$
\left[\begin{array}{l}
v_{a} \\
v_{b} \\
v_{c}
\end{array}\right]=\left[\begin{array}{cr}
2 / 3 & 0 \\
-1 / 3 & 1 / \sqrt{3} \\
-1 / 3 & -1 / \sqrt{3}
\end{array}\right]\left[\begin{array}{c}
v_{\alpha} \\
v_{\beta}
\end{array}\right]
$$

The required DC-link voltage for the dual-inverter scheme to run a three-phase induction motor with a rated phase voltage of $\mathrm{V}_{\mathrm{mot}}$ (rms) may be determined from the requirement that :

$$
V_{d c} / 2=v_{\text {ph, peak }}=\sqrt{2} * V_{\text {mot }}
$$

In the dual inverter configuration, a DC-link voltage of $V_{d c} / 2$ for each inverter ensures that $|O G|=V_{d c}$ ( Fig.4). This implies that the maximum value of the reference space phasor is $3 / 4 * V_{\mathrm{dc}}$, corresponding to the radius of the largest circle inscribed in the hexagon HJLNQS (Fig.4). Consequently, for the proposed scheme a DC-link voltage of $325(\sqrt{ } 2 * 230)$ volts is needed to obtain an output phase voltage of $230 \mathrm{~V}(\mathrm{rms})$, while being in modulation. With overmodulation or six-step mode of operation the rated voltage of the drive motor can be obtained with a lesser DC-link voltage (lesser than $325 \mathrm{~V}$ for a $230 \mathrm{~V}$ motor).

\section{The space-vector PWM strategy to suppress the zero-sequence currents}

It is possible to eliminate the zero-sequence currents by the exclusive use of the space-vector combinations situated at the vertices of the hexagon 'HJLNQS' and two combinations at the center of this hexagon (Fig.4).

An enhanced DC-bus voltage compensates the reduction in the value of the fundamental component of the output of the dual-inverter scheme as discussed in the previous section. Thus, the combinations used in the present work are 13', 64', 24', 15', 35', 26', 46', 31', 51', 42', 53', 62', 77' and 88', i.e. a total of fourteen combinations. From table-1, it may be noted that for these combinations the zero-sequence voltages and consequently the zero-sequence currents are zero. There exist two alternative sets of space-vector combinations. The first set consists of the combinations 13', 24', 35', 46', 51' and 62' along with the combinations 77' and 88' available at the center. The second set is formed by the combinations - 64', 15', 26', 31', 42' and 53' along with the combinations $77^{\prime}$ and $88^{\prime}$. Whichever be the set used, both inverters are sequentially switched through the states - ' 1 ' (+ - -) through ' 6 ' $(+-+)$. It may be noted that the state assumed by inverter- 2 is either lagging or leading that of the state assumed by inverter- 1 by an angle of $120^{\circ}$ (Fig.5). For example, when inverter-1 assumes the state ' 1 ' i.e. (+ - -), inverter-2 assumes either the state ' 3 ' (- + -) as in the first set or the state ' 5 ' $\left(--_{-+}\right)$as in the second set. This explains as to why the harmonic voltages of the triplen order are eliminated in the phase voltage of the dual inverter scheme when a switching takes place amongst these combinations. A phase difference of $120^{\circ}$ between the fundamental components of the individual inverter outputs corresponds to a phase difference of $3 * n * 120^{\circ}$, i.e. an integral multiple of $360^{\circ}$, for the triplen harmonics. Thus, the phase voltage of the dual inverter scheme obtained by taking the difference of the pole voltages of the individual inverters does not contain the voltage harmonics of the triplen order.

Fig.5a depicts the hexagon 'HJLNQS' along with the phase axes A, B, C and the axes that are orthogonal to these axes - the ' $j \mathrm{~A}$ ', the ' $\mathrm{jB}$ ' and the ' $\mathrm{jC}$ ' axes. The length of each side of this hexagon is $\sqrt{3} / 2 * \mathrm{Vdc}$. The sectors of this hexagon are numbered 'I' through 'VI'. For convenience, the $\alpha$ - axis is placed along the 'jA' axis (Fig.5a). 
The reference voltage vector $\mathbf{O P}$ is of magnitude $\left|\mathbf{V}_{\mathrm{sr}}\right|$ and subtends an angle of ' $\alpha$ ' with the $\alpha$ - axis as shown in Fig.5a. The symbols $\mathrm{V}_{\text {asr }}, \mathrm{V}_{\mathrm{bsr}}$ and $\mathrm{V}_{\mathrm{csr}}$ respectively denote the instantaneous reference phase voltages and are obtained by multiplying the respective projections of the reference vector $\mathbf{O P}$ on to the phase axes - A, B and C with a factor of '2/3' (eqn.5 and Fig.5a). Alternatively, the reference vector $\mathbf{O P}$ can be produced by employing the instantaneous reference phase voltages $-\mathrm{V}_{\mathrm{jasr}}, \mathrm{V}_{\mathrm{jbsr}}$ and $\mathbf{V}_{\mathrm{jcsr}}$ obtained by projecting $\mathbf{O P}$ on to the orthogonal axes 'jA', 'jB' and 'jC' (eqn.5 and Fig.5a). From Fig.5, the expressions for the normal and orthogonal instantaneous reference phase values may be obtained as follows:

$$
\begin{aligned}
v_{a s r} & =(2 / 3) *\left|v_{s r}\right| * \cos \left(270^{0}-\alpha\right) \\
v_{b s r} & =(2 / 3) *\left|v_{s r}\right| * \cos \left(30^{0}-\alpha\right) \\
v_{c s r} & =(2 / 3) *\left|v_{s r}\right| * \cos \left(150^{0}-\alpha\right) \\
v_{j a s r} & =(2 / 3) *\left|v_{s r}\right|^{*} \cos \alpha \\
v_{j b s r} & =(2 / 3) *\left|v_{s r}\right|^{*} \cos \left(120^{0}-\alpha\right) \\
v_{j c s r} & =(2 / 3) *\left|v_{s r}\right|^{*} \cos \left(240^{0}-\alpha\right)
\end{aligned}
$$

From eqn.s ( 7 ) and ( 8 ) the relation between these two sets of instantaneous phase references can be obtained as:

$$
\left[\begin{array}{c}
v_{j a s r} \\
v_{j b s r} \\
v_{j c s r}
\end{array}\right]=(1 / \sqrt{3}) *\left[\begin{array}{rrr}
0 & 1 & -1 \\
-1 & 0 & 1 \\
1 & -1 & 0
\end{array}\right]\left[\begin{array}{c}
v_{a s r} \\
v_{b s r} \\
v_{c s r}
\end{array}\right]
$$

The active switching times $T_{1}$ and $T_{2}$ to produce OP in sector-I for the dual-inverter scheme are obtained by applying the volt-sec balance along the $\alpha$ - and the $\beta$ - axes of the dual-inverter scheme. In the following analysis, the symbol $\mathrm{T}_{\mathrm{s}}$ denotes the sampling time interval over which the reference voltage vector OP is assumed to be stationary.

By applying the volt-sec balance along the $\alpha$ - axis:

$$
(\sqrt{3} / 2) * V_{d c} * T_{1}+(\sqrt{3} / 2) * V_{d c} * \cos 60^{0} * T_{2}=v_{\alpha} * T_{s}
$$

By applying the volt-sec balance along the $\beta$ - axis:

$$
\begin{aligned}
& (\sqrt{3} / 2) * V_{d c} * \cos 30^{0} * T_{2}=v_{\beta} * T_{s} \\
& \text { where } v_{\alpha}=(3 / 2) * v_{j a s r} \text { and } v_{\beta}=(\sqrt{3} / 2) *\left(v_{j b s r}-v_{j c s r}\right)
\end{aligned}
$$

Upon the substitution of eqn.s (9) and (12) in eqn.s (10) and (11),

$$
\begin{aligned}
& T_{1}=(2 / 3) *\left(T_{s} / V_{d c}\right) *\left\{\left(v_{b s r}-v_{c s r}\right)-\left(v_{c s r}-v_{a s r}\right)\right\} \text { and } \\
& T_{2}=(2 / 3) *\left(T_{s} / V_{d c}\right) *\left\{\left(v_{c s r}-v_{a s r}\right)-\left(v_{a s r}-v_{b s r}\right)\right\}
\end{aligned}
$$


Similar expressions for the active vector switching times may be obtained for the rest of the sectors of the hexagon 'HJLNQS'. These expressions are tabulated in Table-2.

To implement the proposed PWM strategy, it is required to find out the instantaneous reference phase voltages for the individual inverters. The symbols $\mathrm{V}_{\mathrm{asr} 1}, \mathrm{~V}_{\mathrm{bsr1}}$ and $\mathrm{V}_{\mathrm{csr} 1}$ denote these references for inverter- 1 and the symbols $\mathrm{V}_{\mathrm{asr} 2}, \mathrm{~V}_{\mathrm{bsr}}$ and $\mathrm{V}_{\mathrm{csr} 2}$ denote the same for inverter-2. It can easily be shown that the reference voltage vector of magnitude $\left|\mathrm{V}_{\mathrm{sr}}\right|$ for the dual inverter scheme transforms to a magnitude of $\left|\mathrm{V}_{\mathrm{sr}}\right| / \sqrt{3}$ for individual inverters. Fig.5 shows the $\alpha$ - and the $\beta$ - axes for the individual inverters along with the corresponding sector numbers. The sectors are numbered ' 1 ' through ' 6 ' for inverter- 1 and ' 1 ' ' through ' 6 ' ' for inverter-2. It may be noted that the respective $\alpha$ - axes are displaced by an angle of $120^{\circ}$. It may also be noted that the reference voltage vector of the dual-inverter scheme is the vector sum of the reference voltage vectors of the individual inverters. From the figures $5 \mathrm{a}, 5 \mathrm{~b}$ and $5 \mathrm{c}$ it can be observed that $\mathbf{O P}$ is the reference voltage vector for the dual-inverter scheme. $\mathbf{O P}_{\mathbf{1}}$ and $\mathbf{O P}_{\mathbf{2}}$ respectively are the reference voltage vectors for the inverter- 1 and inverter- 2 . All these reference voltage vectors subtend an angle of ' $\alpha$ ' from the respective $\alpha$ - axes.

$\overrightarrow{\mathrm{OP}}=\overrightarrow{\mathrm{OP}_{1}}+\overrightarrow{\mathrm{OP}_{2}}$

where

$\overrightarrow{\mathrm{OP}}=\left|v_{s r}\right| \angle \alpha$, $\alpha$ mesured from the $\alpha$-axis of the dual-inverter scheme

$\overrightarrow{\mathrm{OP}_{1}}=\left(\left|v_{s r}\right| / \sqrt{3}\right) \angle \alpha, \alpha$ mesured from the $\alpha_{1}$-axis of inverter -1 and

$\overrightarrow{\mathrm{OP}_{2}}=\left(\left|v_{s r}\right| / \sqrt{3}\right) \angle \alpha, \alpha$ mesured from the $\alpha_{2}$-axis of inverter -2 (Fig.5).

Using the $\alpha$ - axis of the dual-inverter scheme that is placed along the 'jA' - axis, as the axis of common reference, eqn.14 may be written as:

$\left|v_{s r}\right| \angle \alpha=\left(\frac{\left|v_{s r}\right|}{\sqrt{3}}\right) \angle\left(30^{0}+\alpha\right)+\left(\frac{\left|v_{s r}\right|}{\sqrt{3}}\right) \angle\left(150^{0}+\alpha\right)$

The above equation serves as a useful crosscheck for the foregoing analysis.

The instantaneous reference phase voltages for inverter- 1 may be obtained by projecting $\mathbf{O P}_{\mathbf{1}}$ on to the phase axes A1, B1 and C1 and multiplying these projections by a factor of '2/3' (eqn.5, Fig.5). A similar procedure may be adopted to determine the instantaneous reference phase voltages for inverter- 2 .

For inverter-1,

$$
\begin{aligned}
& v_{a s r 1}=(2 / 3) *\left(\frac{\left|v_{s r}\right|}{\sqrt{3}}\right) * \cos \left(120^{\circ}+\alpha\right) \\
& v_{b s r 1}=(2 / 3) *\left(\frac{\left|v_{s r}\right|}{\sqrt{3}}\right) * \cos \alpha \\
& v_{c s r 1}=(2 / 3) *\left(\frac{\left|v_{s r}\right|}{\sqrt{3}}\right) * \cos \left(120^{0}-\alpha\right) .
\end{aligned}
$$

For inverter-2,

$$
\begin{aligned}
& v_{a s r 2}=(2 / 3) *\left(\frac{\left|v_{s r}\right|}{\sqrt{3}}\right) * \cos \left(240^{0}+\alpha\right) \\
& v_{b s r 2}=(2 / 3) *\left(\frac{\left|v_{s r}\right|}{\sqrt{3}}\right) * \cos \left(120^{0}+\alpha\right) \\
& v_{c s r 2}=(2 / 3) *\left(\frac{\left|v_{s r}\right|}{\sqrt{3}}\right) * \cos \alpha
\end{aligned}
$$


From eqn.16 and eqn.17 it may be noted that

$$
\begin{aligned}
& v_{a s r 2}=v_{c s r 1} \\
& v_{b s r 2}=v_{a s r 1} \\
& v_{c s r 2}=v_{b s r 1}
\end{aligned}
$$

It can be verified that the instantaneous reference phase voltages for the dual-inverter scheme ( $\mathrm{V}_{\mathrm{asr}}, \mathrm{v}_{\mathrm{bsr}}$ and $\mathrm{v}_{\mathrm{csr}}$ ) are obtained by subtracting the instantaneous reference phase voltages of inverter- 2 from those of the inverter-1:

$$
\begin{aligned}
& v_{a s r}=v_{a s r 1}-v_{a s r 2} \\
& v_{b s r}=v_{b s r 1}-v_{b s r 2} \\
& v_{c s r}=v_{c s r 1}-v_{c s r 2}
\end{aligned}
$$

From the equations 18 and 19 the instantaneous reference phase voltages of individual inverters may be expressed in terms of the instantaneous reference phase voltages of the dual-inverter scheme:

$$
\begin{aligned}
& v_{a s r 1}=(1 / 3)\left(v_{a s r}-v_{b s r}\right) \\
& v_{b s r 1}=(1 / 3)\left(v_{b s r}-v_{c s r}\right) \\
& v_{c s r 1}=(1 / 3)\left(v_{c s r}-v_{a s r}\right)
\end{aligned}
$$

From eqn.18 and eqn.20,

$$
\begin{aligned}
& v_{a s r 2}=(1 / 3)\left(v_{c s r}-v_{a s r}\right) \\
& v_{b s r 2}=(1 / 3)\left(v_{a s r}-v_{b s r}\right) \\
& v_{c s r 2}=(1 / 3)\left(v_{b s r}-v_{c s r}\right)
\end{aligned}
$$

Substituting eqn.20 in eqn.13, the active vector switching timings T1 and T2 in sector-I of the dual-inverter scheme may be expressed solely in terms of the instantaneous reference phase voltages of inverter-1.

$$
\begin{aligned}
& T_{1}=\left(\frac{T_{s}}{V_{d c} / 2}\right)\left\{v_{b s r 1}-v_{c s r 1}\right\} \\
& T_{2}=\left(\frac{T_{s}}{V_{d c} / 2}\right)\left\{v_{c s r 1}-v_{a s r 1}\right\}
\end{aligned}
$$

Similarly up on the substitution of eqn.21 in eqn.13, the active vector switching timings $T_{1}$ and $T_{2}$ in sector-I of the dual-inverter scheme may be evaluated in terms of the instantaneous reference phase voltages of inverter- 2 .

$$
\begin{aligned}
& T_{1}=\left(\frac{T_{s}}{V_{d c} / 2}\right)\left\{v_{c s r 2}-v_{a s r 2}\right\} \\
& T_{2}=\left(\frac{T_{s}}{V_{d c} / 2}\right)\left\{v_{a s r 2}-v_{b s r 2}\right\}
\end{aligned}
$$


The active vector switching timings $T_{1}$ and $T_{2}$ can also be evaluated in the same way for the rest of the sectors of the dual-inverter scheme.

Though eqn.s (22) and (23) express the active vector switching times $\left(\mathrm{T}_{1}\right.$ and $\left.\mathrm{T}_{2}\right)$ in terms of the instantaneous reference phase voltages of the individual inverters, it is tedious to implement the PWM strategy. This is a consequence of the fact that it is required to find out the sector in which the tip of $\mathbf{O P}$, the reference voltage vector for the dual-inverter scheme, is situated (or the tips of $\mathbf{O P}_{\mathbf{1}}$ and $\mathbf{O P}_{\mathbf{2}}$ for the individual inverters). A simple and elegant strategy is proposed in [4], which eliminates the necessity to identify the sector. Though this strategy is proposed for a conventional (single-inverter) scheme in [4], it can easily be extended to the dual-inverter scheme. In this method, only the instantaneous reference phase voltages are required to generate the space-vector based PWM waveforms. This method is briefly described in the following paragraphs for the generation of the space-vector based PWM generation for the inverter- 1 . The same method is applicable to the inverter- 2 also, as the instantaneous reference phase voltages for inverter- 2 are displaced by $120^{\circ}$ w.r.t. those of the inverter-1.

Imaginary switching times for the inverter-1 and inverter-2 are defined as [4]:

$$
\begin{aligned}
& T_{a s 1} \equiv\left(\frac{T_{s}}{V_{d c} / 2}\right) * v_{a s r 1} ; \quad T_{a s 2} \equiv\left(\frac{T_{s}}{V_{d c} / 2}\right) * v_{a s r 2} \\
& T_{b s 1} \equiv\left(\frac{T_{s}}{V_{d c} / 2}\right) * v_{b s r 1} ; \quad T_{b s 2} \equiv\left(\frac{T_{s}}{V_{d c} / 2}\right) * v_{b s r 2} \\
& T_{c s 1} \equiv\left(\frac{T_{s}}{V_{d c} / 2}\right) * v_{c s r 1} ; \quad T_{c s 2} \equiv\left(\frac{T_{s}}{V_{d c} / 2}\right) * v_{c s r 2} \text {; }
\end{aligned}
$$

From the above definitions, it may be noted that the imaginary switching times are proportional to the instantaneous value of the reference voltage space phasor.

From eqn.s (22) and (24) the active vector switching times $T_{1}$ and $T_{2}$ in sector-1 (inverter-1) may be expressed as:

$$
\begin{aligned}
& T_{1}=T_{b s 1}-T_{c s 1} \\
& T_{2}=T_{c s 1}-T_{a s 1}
\end{aligned}
$$

From eqn.s (23) and (24) the active vector switching times $T_{1}$ and $T_{2}$ in sector-1' (inverter-2) may be expressed as:

$$
\begin{aligned}
& T_{1}=T_{c s 2}-T_{a s 2} \\
& T_{2}=T_{a s 2}-T_{b s 2}
\end{aligned}
$$

Extending this procedure for the other sectors of the inverter-1 hexagon, the active vector switching times $T_{1}$ and $T_{2}$ for the respective sectors may be expressed in terms of the imaginary switching times $T_{\text {as1 }}, T_{\text {bs1 }}$ and $T_{\text {cs } 1}$ for a particular sampling interval. Table- 3 shows the relation ship between these timings and the instantaneous reference phase voltages of inverter- 1 and those of inverter- 2 .

The effective time - $\mathrm{T}_{\text {eff }}$ is the total time duration in which the active vectors are switched in a sector and is given by $\left(T_{1}+T_{2}\right)$. This may be determined as the difference between the maximum and minimum values among $T_{\text {as1 }}, T_{\text {bs1 }}$ and $T_{\text {cs } 1}$. The time duration $T_{0}$, the time for which a zero vector is applied, may be obtained from $T_{1}$ and $T_{2}$ as:

$$
T_{0}=\left(T_{s}-T_{e f f}\right)
$$




$$
\begin{aligned}
& T_{e f f} \equiv T_{\max }-T_{\min } \\
& T_{\max } \equiv \max \left\{T_{a s 1}, T_{b s 1}, T_{c s 1}\right\} \\
& T_{\min } \equiv \min \left\{T_{a s 1}, T_{b s 1}, T_{c s 1}\right\}
\end{aligned}
$$

The offset time $T_{\text {offset }}$ required to distribute the zero voltage symmetrically during one sampling period is given by [4] :

$$
T_{\text {offset }}=\left(T_{0} / 2\right)-T_{\min }
$$

The actual switching times for each the inverter leg can be obtained by the time shifting operation as follows:

$$
\begin{aligned}
T_{\text {ga } 1} & =T_{a s 1}+T_{\text {offset }} \\
T_{g b 1} & =T_{b s 1}+T_{\text {offset }} \\
T_{g c 1} & =T_{c s 1}+T_{\text {offset }}
\end{aligned}
$$

A similar procedure is adopted for inverter- 2 as the instantaneous reference phase voltages for the inverter-2 are related to those for the inverter-1 through eqn.18. It may be noted that in the foregoing analysis, the instantaneous reference phase voltages for the inverter-2 lead those of the inverter- 1 by $120^{\circ}$. Consequently, the space-vector modulation for the dual-inverter scheme is realized with the active vector combinations of 13', 24', 35', 46', 51' and 62 ' (set - 1) and the zero-vector combinations - 77' and 88'. Alternatively, the instantaneous reference phase voltages for the inverter- 2 may be made to lag those for the inverter- 1 by $120^{\circ}$ to realize the space vector modulation for the dual-inverter scheme with the active vector combinations of 64', 15', 26', 31', 42' and 53' (set-2) and the zerovector combinations - 77' and 88'. Table-4 and table-5, respectively, present the switching patterns using the set-1 and the set-2. Generation of a typical switching pattern, when the tip of the voltage reference space phasor $\mathbf{O P}_{\mathbf{1}}$, of inverter-1, is situated in sector-5 is shown in Fig.6.

\section{Experimental verification and discussion}

The proposed dual-inverter scheme is implemented with a DC-bus voltage of $325 \mathrm{~V}$ ( for both the inverters) for a 1-HP, 3-phase open-end winding induction motor. The V/f control scheme has been employed for the speed control of the induction motor. The instantaneous reference phase voltages $-\mathrm{v}_{\mathrm{asr}}$, $\mathrm{v}_{\mathrm{bsr}}$ and $\mathrm{v}_{\mathrm{csr}}$ to realize the reference voltage vector $\mathbf{O P}$ for the dual-inverter scheme (Fig.5), are sampled at regular intervals of $7.5^{0}$ i.e. with a sampling frequency of 48-samples per cycle as illustrated in Fig.7. The references for the dual-inverter scheme $\left(\mathrm{V}_{\mathrm{asr}}, \mathrm{v}_{\mathrm{bsr}}\right.$ and $\mathrm{V}_{\mathrm{csr}}$ ) are then resolved into the instantaneous reference phase voltages for the individual inverters using eqn.s 20 and 21 (Fig.7). It may be noted that the sampling time interval $\left(T_{s}\right)$ is a variable quantity depending upon the frequency of operation (or the desired speed in a V/f controlled drive). The gating signal generation has been accomplished by the use of TMS320F240 DS processor.

The experimental results are presented for the following modes of operation:

\section{i) Linear modulation:}

The tip of the reference voltage space phasor OP located in the inner hexagon 'HJLNQS' (Fig.5) sampling at points that are spaced $7.5^{0}$ apart i.e. with 48 samples in a cycle of operation (Fig.7).

When the dual-inverter scheme is made to operate in this region, there exists a linear relationship between the value of $|\mathbf{O P}|$ and the value of the fundamental component in the output of the dual-inverter scheme. The index of modulation for the dual-inverter scheme is given by: 


$$
m_{a}(\text { dual })=\left(\frac{|\mathbf{O P}|}{\sqrt{3} / 2 * V_{d c}}\right)
$$

As explained earlier, a reference of value $|\mathbf{O P}|$ gets transformed into a reference of value $|\mathbf{O P}| / \sqrt{ } 3$ for the individual inverters. Each inverter is operated with a DC-bus voltage of $\mathrm{V}_{\mathrm{dc}} / 2$. Hence the modulation index for each inverter is given by:

$$
\left.m_{a} \text { (individual }\right)=\left(\frac{|\mathbf{O P}| / \sqrt{3}}{V_{d c} / 2}\right)=\left(\frac{|\mathbf{O P}|}{\sqrt{3} / 2 * V_{d c}}\right)=m_{a}(\text { dual })
$$

The concurrence of eqn.30 and eqn.31 further validates the analysis presented in the previous section - that the actual instantaneous reference phase voltages for the dual-inverter scheme $\left(\mathrm{V}_{\mathrm{asr}}, \mathrm{V}_{\mathrm{bsr}}\right.$, and $\mathrm{V}_{\mathrm{csr}}$ ) may be translated into the instantaneous reference phase voltages of individual inverters $\left(\mathrm{V}_{\mathrm{asr} 1}, \mathrm{v}_{\mathrm{bsr1}}, \mathrm{v}_{\mathrm{csr} 1}, \mathrm{v}_{\mathrm{asr} 2}, \mathrm{v}_{\mathrm{bsr} 2}\right.$ and $\left.\mathrm{v}_{\mathrm{csr} 2}\right)$ for the sake of implementation.

Fig.8 illustrates the simulation results and the experimental results when the dual-inverter scheme is operated in the linear modulation range with a modulation index of 0.75 , which means:

$$
\begin{aligned}
& \frac{\left|\mathbf{O P}_{\mathbf{1}}\right|}{\left(V_{d c} / 2\right)}=\frac{\left|\mathbf{O P}_{\mathbf{2}}\right|}{\left(V_{d c} / 2\right)}=\frac{|\mathbf{O P}|}{\left(\sqrt{3} V_{d c} / 2\right)}=0.75 \\
& \text { as }|\mathbf{O P}|=\sqrt{3}\left|\mathbf{O P}_{\mathbf{1}}\right|=\sqrt{3}\left|\mathbf{O P}_{\mathbf{2}}\right|
\end{aligned}
$$

The above condition corresponds to

$$
|\mathbf{O P}|=(\sqrt{3} / 2) V_{d c} \approx 0.65 V_{d c}
$$

Fig.8a and Fig.8b show the simulated pole voltage waveforms $\mathrm{V}_{\mathrm{ao}}$ and $\mathrm{V}_{\mathrm{a}}$ of of the individual inverters, when the dual-inverter scheme is operated with a modulation index of 0.75 ( $|\mathbf{O P}|=0.65 \mathrm{Vdc}$, eqn. 33). Fig. 8c shows the waveform of phase voltage $\mathrm{V}_{\text {aa' }}$ which is obtained subtracting the waveform of $\mathbf{V}_{\mathrm{a}^{\prime} \mathrm{o}}$ (Fig.8b) from that of $\mathrm{V}_{\mathrm{ao}}\left(\mathrm{V}_{\mathrm{aa}}=\right.$ $\mathrm{V}_{\mathrm{ao}}-\mathrm{V}_{\mathrm{a}^{\prime} \mathrm{o}}$ ). Similarly the instantaneous phase voltage waveforms $\mathrm{V}_{\mathrm{bb}^{\prime}}$ and $\mathrm{V}_{\mathrm{Cc}^{\prime}}$ are also obtained. The triplen harmonic content $\mathrm{V}_{\mathrm{zs}}$ is then obtained by using the eqn.1. Fig.8d shows the triplen harmonic content $\mathrm{V}_{\mathrm{zs}}$ for this operating condition. It may be noted that the zero sequence content (the triplen harmonic content) of the three phase system with instantaneous phase voltages of $\mathrm{V}_{\mathrm{aa}}$, $\mathrm{v}_{\mathrm{bb}}$, and $\mathrm{V}_{\mathrm{cc}}$ is zero.

The Figures 8e through 8h illustrate the experimental results at this operating condition. Fig.8e shows the gating waveforms for the top devices of the A-phase legs of the individual inverters, which are identical (though scaleddown) to the waveforms $-\mathrm{V}_{\mathrm{ao}}$ and $\mathrm{V}_{\mathrm{a}}$ o. Fig.8f shows the phase voltage waveform $\mathrm{V}_{\mathrm{aa}}$. It may be observed that this waveform is in agreement with the one obtained by simulation (Fig.8c). Fig.8g shows the phase current of the motor, which is approximately sinusoidal. Fig.8h shows the normalized harmonic spectrum of the motor phase voltage $\mathrm{V}_{\text {aa' }}$ (Fig.8f). It may be observed that the triplen harmonic components are absent in this spectrum, thus validating the objective of the PWM strategy.

\section{ii) Over-modulation:}

In this operational mode, the tip of $\mathbf{O P}$ traces the outer hexagon 'HJLNQS' (Fig.5) sampling at points that are spaced $7.5^{\circ}$ apart i.e. with 48 samples in a cycle of operation (Fig.7). When the tip of OP lies outside the outer hexagon, it is forced to trace the periphery of the outer hexagon [4]. Fig.9 illustrates the simulation results and the experimental results when the dual-inverter scheme is operated in the mode of over-modulation. 
Fig.9 shows the same waveforms when the dual-inverter scheme is operated in over-modulation. It may be noted that in this case also, the experimentally obtained phase voltage $V_{a a}$ (Fig.9f) concurs with the one obtained by simulation (Fig.9c). The simulated waveform of $\mathrm{v}_{\mathrm{zs}}$ (Fig.9d) indicates the absence of the zero-sequence voltages in the phase voltage $\mathrm{V}_{\mathrm{aa}}$ and the normalized harmonic spectrum of the experimentally obtained phase voltage $\mathrm{V}_{\mathrm{aa}}$ (Fig.9h) confirms this assertion.

\section{iii) The six-step operation}

The tip of OP tracing the outer hexagon 'HJLNQS', sampling only at points that are spaced $60^{\circ}$ apart along the periphery of the outer hexagon, i.e. at points 'H', 'J', 'L','N','Q' and 'S' (Fig.5). It is obvious that the dual inverter scheme exhibits the maximum voltage capability in this mode of operation. Fig.10 illustrates the experimental results when the dual-inverter scheme is operated in this mode. Simulation results have not been presented in this case, as this operating mode is too well known.

Fig. 10a, 10b and 10c respectively show the experimentally obtained waveforms - pole voltage waveforms $\mathrm{V}_{\mathrm{ao}}$ and $\mathrm{V}_{\mathrm{a}}$ o of the individual inverters, the phase voltage $\mathrm{V}_{\mathrm{aa}}$ and the motor phase current at no-load. The phase difference of $120^{\circ}$ between $V_{a o}$ and $V_{a}$ io is evident from Fig.10a. This phase shift cancels out the triplen harmonics in the phase voltage.

\section{Conclusion}

- In this paper a space-vector based PWM strategy has been proposed for a dual two-level inverter fed open-end winding induction motor drive. The proposed PWM cancels out the common mode voltages and thus the common mode currents (harmonics of the triplen order) in the phases of the induction motor. This eliminates the need for isolation transformers or harmonic filters for the suppression of the triplen harmonic currents.

- The proposed space vector PWM is based on the observation that certain voltage space-vector combinations in the dual inverter scheme do not contribute to the triplen harmonics and hence the PWM scheme that exclusively employs these combinations achieves the elimination of the triplen harmonic components.

- A simple and elegant switching scheme is employed for the implementation of the space-vector modulation, which requires only the instantaneous values of the reference phase voltages.

- The simulation results and the experimental results are presented for the entire range of operation - undermodulation, over-modulation and the six-step operation.

\section{References}

[1] H.Stemmler, P.Guggenbach, "Configurations of High Power Voltage Source Inverter Drives", EPE.conf-1993, pp. 7 - 12.

[2] Haonan Zhang, Annet von Jonanne, Shaoon Dai, Alan K. Wallace, Fei Wang, "Multi-level inverters modulation schemes to eliminate common-mode voltages", IEEE Trans. on IA - vol.36, Nov./Dec.2000, pp. 1645 - 1653.

[3] E.G.Shivakumar, K.Gopakumar, S.K.Sinha, Andre Pittet, V.T.Ranganathan: Space vector PWM Control of Dual-Inverter fed Open-end Winding Induction Motor Drive. IEEE-APEC-2001, pp. 399 405.

[4] Joohn-Sheok Kim, Seung-Ki Sul, ” A Novel Voltage Modulation Technique of the Space Vector PWM”, IPEC-1995, pp. 742 - 747. 
Table - 2

\begin{tabular}{|c|c|c|}
\hline Sector No. & $\mathbf{T}_{1}$ & $\mathbf{T}_{2}$ \\
\hline 1 & $(2 / 3)\left(T_{s} / V_{d c}\right)\left[\left(v_{b}-V_{c}\right)-\left(v_{c}-v_{a}\right)\right]$ & $(2 / 3)\left(T_{s} / V_{d c}\right)\left[\left(v_{c}-V_{a}\right)-\left(v_{a}-v_{b}\right)\right]$ \\
\hline 2 & $(2 / 3)\left(T_{s} / V_{d c}\right)\left[\left(v_{b}-V_{a}\right)-\left(v_{c}-v_{b}\right)\right]$ & $(2 / 3)\left(T_{s} / V_{d c}\right)\left[\left(v_{c}-v_{b}\right)-\left(v_{a}-v_{c}\right)\right]$ \\
\hline 3 & $(2 / 3)\left(T_{s} / V_{d c}\right)\left[\left(v_{c}-v_{a}\right)-\left(v_{a}-V_{b}\right)\right]$ & $(2 / 3)\left(T_{s} / V_{d c}\right)\left[\left(v_{a}-v_{b}\right)-\left(v_{b}-v_{c}\right)\right]$ \\
\hline 4 & $(2 / 3)\left(T_{s} / V_{d c}\right)\left[\left(v_{c}-v_{b}\right)-\left(v_{a}-v_{c}\right)\right]$ & $(2 / 3)\left(T_{s} / V_{d c}\right)\left[\left(v_{a}-v_{c}\right)-\left(v_{b}-v_{a}\right)\right]$ \\
\hline 5 & $(2 / 3)\left(T_{s} / V_{d c}\right)\left[\left(v_{a}-v_{b}\right)-\left(v_{b}-v_{c}\right)\right]$ & $(2 / 3)\left(T_{s} / V_{d c}\right)\left[\left(v_{b}-v_{c}\right)-\left(v_{c}-v_{a}\right)\right]$ \\
\hline 6 & $(2 / 3)\left(T_{s} / V_{d c}\right)\left[\left(v_{a}-V_{c}\right)-\left(v_{b}-V_{a}\right)\right]$ & $(2 / 3)\left(T_{s} / V_{d c}\right)\left[\left(v_{b}-v_{a}\right)-\left(v_{c}-v_{b}\right)\right]$ \\
\hline
\end{tabular}

\section{Table-3}

\begin{tabular}{|c|c|c|c|c|c|c|}
\hline & \multicolumn{6}{|c|}{ In terms of the instantaneous reference phase voltages of inverter-1 } \\
\hline & Sector - 1 & Sector - 2 & Sector - 3 & Sector - 4 & Sector -5 & Sector - 6 \\
\hline $\mathbf{T}_{\mathbf{1}}$ & $\left(T_{b s 1}-T_{c s 1}\right)$ & $\left(T_{\text {bs1 } 1}-T_{\text {as1 }}\right)$ & $\left(T_{c s 1}-T_{\text {as1 }}\right)$ & $\left(T_{\text {cs1 } 1}-T_{b s 1}\right)$ & $\left(T_{\text {as1 } 1}-T_{b s 1}\right)$ & $\left(T_{\text {as1 }}-T_{c s 1}\right)$ \\
\hline $\mathbf{T}_{2}$ & $\left(T_{\text {cs1 }}-T_{\text {as1 }}\right)$ & $\left(T_{c s 1}-T_{b s 1}\right)$ & $\left(T_{a s 1}-T_{b s 1}\right)$ & $\left(T_{\text {as1 }}-T_{\text {cs1 }}\right)$ & $\left(T_{b s 1}-T_{c s 1}\right)$ & $\left(T_{\text {bs1 }}-T_{\text {as1 }}\right)$ \\
\hline
\end{tabular}

\begin{tabular}{|c|c|c|c|c|c|c|}
\hline & \multicolumn{6}{|c|}{ In terms of the instantaneous reference phase voltages of inverter-2 } \\
\hline & Sector - 1' & Sector - 2' & Sector - 3' & Sector - 4' & Sector - 5' & Sector - 6' \\
\hline $\mathbf{T}_{1}$ & $\left(T_{\text {cs2 }}-T_{\text {as2 }}\right)$ & $\left(T_{\text {cs2 } 2}-T_{\text {bs2 }}\right)$ & $\left(T_{\text {as2 }}-T_{\text {bs2 }}\right)$ & $\left(T_{\text {as2 }}-T_{\text {cs2 }}\right)$ & $\left(T_{b s 2}-T_{c s 2}\right)$ & $\left(T_{b s 2}-T_{a s 2}\right)$ \\
\hline $\mathbf{T}_{2}$ & $\left(T_{\text {as2 }}-T_{b s 2}\right)$ & $\left(T_{\text {as2 }}-T_{\text {cs2 }}\right)$ & $\left(T_{b s 2}-T_{c s 2}\right)$ & $\left(T_{b s 2}-T_{\text {as2 } 2}\right)$ & $\left(T_{\text {cs2 }}-T_{\text {as2 } 2}\right)$ & $\left(T_{c s 2}-T_{b s 2}\right)$ \\
\hline
\end{tabular}


Table -4

\begin{tabular}{|c|c|c|c|}
\hline Alpha ( degrees) & \begin{tabular}{ll|} 
Sector & for \\
Inverter - 1 & \\
\end{tabular} & \begin{tabular}{|ll} 
Sector & for \\
Inverter - 2 & \\
\end{tabular} & Switching Sequence \\
\hline 0 & 1 & $3^{\prime}$ & $77^{\prime}-24^{\prime}-13^{\prime}-88^{\prime}$ \\
\hline 7.5 & 1 & $3^{\prime}$ & $88^{\prime}-13^{\prime}-24^{\prime}-77^{\prime}$ \\
\hline 15.0 & 1 & $3^{\prime}$ & $77^{\prime}-24^{\prime}-13^{\prime}-88^{\prime}$ \\
\hline 22.5 & 1 & $3^{\prime}$ & $88^{\prime}-13^{\prime}-24^{\prime}-77^{\prime}$ \\
\hline 30.0 & 1 & $3^{\prime}$ & $77^{\prime}-24^{\prime}-13^{\prime}-88^{\prime}$ \\
\hline 37.5 & 1 & $3^{\prime}$ & $88^{\prime}-13^{\prime}-24^{\prime}-77^{\prime}$ \\
\hline 45.0 & 1 & $3{ }^{\prime}$ & $77^{\prime}-24^{\prime}-13^{\prime}-88^{\prime}$ \\
\hline 52.5 & 1 & $33^{\prime}$ & $88^{\prime}-13^{\prime}-24^{\prime}-77^{\prime}$ \\
\hline 60.0 & 2 & $4^{\prime}$ & $77^{\prime}-24^{\prime}-35$ '- 88' \\
\hline 67.5 & 2 & $4^{\prime}$ & $88^{\prime}-35^{\prime}-24^{\prime}-77^{\prime}$ \\
\hline 75.0 & 2 & $4^{\prime}$ & $77^{\prime}-24^{\prime}-35$ '- 88' \\
\hline 82.5 & 2 & $4^{\prime}$ & $88^{\prime}-35^{\prime}-24^{\prime}-77^{\prime}$ \\
\hline 90.0 & 2 & $4^{\prime}$ & $77^{\prime}-24^{\prime}-35$ '- 88' \\
\hline 97.5 & 2 & $4^{\prime}$ & $88^{\prime}-35^{\prime}-24^{\prime}-77^{\prime}$ \\
\hline 105.0 & 2 & $4^{\prime}$ & $77^{\prime}-24^{\prime}-35$ '- 88' \\
\hline 112.5 & 2 & $4^{\prime}$ & $88^{\prime}-35^{\prime}-24$ '- 77' \\
\hline 120.0 & 3 & $5^{\prime}$ & $77^{\prime}-46^{\prime}-35^{\prime}-88^{\prime}$ \\
\hline 127.5 & 3 & $5^{\prime}$ & $88^{\prime}-35^{\prime}-46^{\prime}-77^{\prime}$ \\
\hline 135.0 & 3 & $5^{\prime}$ & $77^{\prime}-46^{\prime}-35^{\prime}-88^{\prime}$ \\
\hline 142.5 & 3 & $5^{\prime}$ & $88^{\prime}-35^{\prime}-46^{\prime}-77^{\prime}$ \\
\hline 150.0 & 3 & $5^{\prime}$ & $77^{\prime}-46^{\prime}-35^{\prime}-88^{\prime}$ \\
\hline 157.5 & 3 & $5^{\prime}$ & $88^{\prime}-35^{\prime}-46^{\prime}-77^{\prime}$ \\
\hline 165.0 & 3 & $5^{\prime}$ & $77^{\prime}-46^{\prime}-35^{\prime}-88^{\prime}$ \\
\hline 172.5 & 3 & $5^{\prime}$ & $88^{\prime}-35^{\prime}-46^{\prime}-77^{\prime}$ \\
\hline 180.0 & 4 & $6^{\prime}$ & $77^{\prime}-46^{\prime}-51^{\prime}-88^{\prime}$ \\
\hline 187.5 & 4 & $6^{\prime}$ & $88^{\prime}-51^{\prime}-46^{\prime}-77^{\prime}$ \\
\hline 195.0 & 4 & $6^{\prime}$ & $77^{\prime}-46^{\prime}-51^{\prime}-88^{\prime}$ \\
\hline 202.5 & 4 & $6^{\prime}$ & $88^{\prime}-51^{\prime}-46^{\prime}-77^{\prime}$ \\
\hline 210.0 & 4 & $6^{\prime}$ & $77^{\prime}-46^{\prime}-51^{\prime}-88^{\prime}$ \\
\hline 217.5 & 4 & $6^{\prime}$ & $88^{\prime}-51^{\prime}-46^{\prime}-77^{\prime}$ \\
\hline 225.0 & 4 & $6^{\prime}$ & $77^{\prime}-46^{\prime}-51^{\prime}-88^{\prime}$ \\
\hline 232.5 & 4 & $6^{\prime}$ & $88^{\prime}-51^{\prime}-46^{\prime}-77^{\prime}$ \\
\hline 240.0 & 5 & $1^{\prime}$ & $77^{\prime}-62^{\prime}-51^{\prime}-88^{\prime}$ \\
\hline 247.5 & 5 & $1^{\prime}$ & $88^{\prime}-51^{\prime}-62^{\prime}-77^{\prime}$ \\
\hline 255.0 & 5 & $1^{\prime}$ & $77^{\prime}-62^{\prime}-51^{\prime}-88^{\prime}$ \\
\hline 262.5 & 5 & $1^{\prime}$ & $88^{\prime}-51^{\prime}-62^{\prime}-77^{\prime}$ \\
\hline 270.0 & 5 & $1^{\prime}$ & $77^{\prime}-62^{\prime}-51^{\prime}-88^{\prime}$ \\
\hline 277.5 & 5 & $1^{\prime}$ & $88^{\prime}-51^{\prime}-62^{\prime}-77^{\prime}$ \\
\hline 285.0 & 5 & $1^{\prime}$ & $77^{\prime}-62^{\prime}-51^{\prime}-88^{\prime}$ \\
\hline 292.5 & 5 & $1^{\prime}$ & $88^{\prime}-51^{\prime}-62^{\prime}-77^{\prime}$ \\
\hline 300.0 & 6 & $2^{\prime}$ & $77^{\prime}-62^{\prime}-13^{\prime}-88^{\prime}$ \\
\hline 307.5 & 6 & $2^{\prime}$ & $8^{\prime \prime}-13^{\prime}-62^{\prime}-77^{\prime}$ \\
\hline 315.0 & 6 & $2^{\prime}$ & $77^{\prime}-62^{\prime}-13^{\prime}-88^{\prime}$ \\
\hline 322.5 & 6 & $2^{\prime}$ & $88^{\prime}-13^{\prime}-62^{\prime}-77^{\prime}$ \\
\hline 330.0 & 6 & $2^{\prime}$ & $77^{\prime}-62^{\prime}-13^{\prime}-88^{\prime}$ \\
\hline 337.5 & 6 & $2^{\prime}$ & $8^{88^{\prime}-13^{\prime}-62^{\prime}-77^{\prime}}$ \\
\hline 345.0 & 6 & $2^{\prime}$ & $77^{\prime}-62^{\prime}-13^{\prime}-88^{\prime}$ \\
\hline 352.5 & 6 & $2^{\prime}$ & $88^{\prime}-13^{\prime}-62^{\prime}-77^{\prime}$ \\
\hline
\end{tabular}


$\underline{\text { Table }-5}$

\begin{tabular}{|c|c|c|c|}
\hline Alpha ( degrees) & $\begin{array}{l}\text { Sector for } \\
\text { Inverter - 1 }\end{array}$ & $\begin{array}{ll}\text { Sector } & \text { for } \\
\text { Inverter - 2 } & \\
\end{array}$ & Switching Sequence \\
\hline 0 & 6 & $4^{\prime}$ & $77^{\prime}-64^{\prime}-15^{\prime}-88^{\prime}$ \\
\hline 7.5 & 6 & $4^{\prime}$ & $88^{\prime}-15^{\prime}-64^{\prime}-77^{\prime}$ \\
\hline 15.0 & 6 & $4{ }^{\prime}$ & $77^{\prime}-64^{\prime}-15^{\prime}-88^{\prime}$ \\
\hline 22.5 & 6 & $4^{\prime}$ & $88^{\prime}-15^{\prime}-64^{\prime}-77^{\prime}$ \\
\hline 30.0 & 6 & $4^{\prime}$ & $77^{\prime}-64^{\prime}-15^{\prime}-88^{\prime}$ \\
\hline 37.5 & 6 & $4^{\prime}$ & $88^{\prime}-15^{\prime}-64^{\prime}-77^{\prime}$ \\
\hline 45.0 & 6 & $4^{\prime}$ & $77^{\prime}-64^{\prime}-15^{\prime}-88^{\prime}$ \\
\hline 52.5 & 6 & $4^{\prime}$ & $88^{\prime}-15^{\prime}-64^{\prime}-77^{\prime}$ \\
\hline 60.0 & 1 & $5^{\prime}$ & $77^{\prime}-26^{\prime}-15^{\prime}-88^{\prime}$ \\
\hline 67.5 & 1 & $5^{\prime}$ & $88^{\prime}-15^{\prime}-26^{\prime}-77^{\prime}$ \\
\hline 75.0 & 1 & $5^{\prime}$ & $77^{\prime}-26^{\prime}-15^{\prime}-88^{\prime}$ \\
\hline 82.5 & 1 & $5^{\prime}$ & $88^{\prime}-15^{\prime}-26^{\prime}-77^{\prime}$ \\
\hline 90.0 & 1 & $5^{\prime}$ & $77^{\prime}-26^{\prime}-15^{\prime}-88^{\prime}$ \\
\hline 97.5 & 1 & $5^{\prime}$ & $88^{\prime}-15^{\prime}-26^{\prime}-77^{\prime}$ \\
\hline 105.0 & 1 & $5^{\prime}$ & $77^{\prime}-26^{\prime}-15^{\prime}-88^{\prime}$ \\
\hline 112.5 & 1 & $5^{\prime}$ & $88^{\prime}-15^{\prime}-26^{\prime}-77^{\prime}$ \\
\hline 120.0 & 2 & $6^{\prime}$ & $77^{\prime}-26^{\prime}-31^{\prime}-88^{\prime}$ \\
\hline 127.5 & 2 & $6^{\prime}$ & $88^{\prime}-31^{\prime}-26^{\prime}-77^{\prime}$ \\
\hline 135.0 & 2 & $6^{\prime}$ & $77^{\prime}-26^{\prime}-31^{\prime}-88^{\prime}$ \\
\hline 142.5 & 2 & $6^{\prime}$ & $88^{\prime}-31^{\prime}-26^{\prime}-77^{\prime}$ \\
\hline 150.0 & 2 & $6^{\prime}$ & $77^{\prime}-26^{\prime}-31^{\prime}-88^{\prime}$ \\
\hline 157.5 & 2 & $6^{\prime}$ & $88^{\prime}-31^{\prime}-26^{\prime}-77^{\prime}$ \\
\hline 165.0 & 2 & $6^{\prime}$ & $77^{\prime}-26^{\prime}-31^{\prime}-88^{\prime}$ \\
\hline 172.5 & 2 & $6^{\prime}$ & $88^{\prime}-31^{\prime}-26^{\prime}-77^{\prime}$ \\
\hline 180.0 & 3 & $1^{\prime}$ & $77^{\prime}-42^{\prime}-31^{\prime}-88^{\prime}$ \\
\hline 187.5 & 3 & $1^{\prime}$ & $88^{\prime}-31^{\prime}-42^{\prime}-77^{\prime}$ \\
\hline 195.0 & 3 & $1^{\prime}$ & $77^{\prime}-42^{\prime}-31^{\prime}-88^{\prime}$ \\
\hline 202.5 & 3 & $1^{\prime}$ & $88^{\prime}-31^{\prime}-42^{\prime}-77^{\prime}$ \\
\hline 210.0 & 3 & $1^{\prime}$ & $77^{\prime}-42^{\prime}-31^{\prime}-88^{\prime}$ \\
\hline 217.5 & 3 & $1^{\prime}$ & $88^{\prime}-31^{\prime}-42^{\prime}-77^{\prime}$ \\
\hline 225.0 & 3 & $1^{\prime}$ & $77^{\prime}-42^{\prime}-31^{\prime}-88^{\prime}$ \\
\hline 232.5 & 3 & $1^{\prime}$ & $88^{\prime}-31^{\prime}-42^{\prime}-77^{\prime}$ \\
\hline 240.0 & 4 & $2^{\prime}$ & $77^{\prime}-42^{\prime}-53^{\prime}-88^{\prime}$ \\
\hline 247.5 & 4 & $2^{\prime}$ & $88^{\prime}-53^{\prime}-42^{\prime}-77^{\prime}$ \\
\hline 255.0 & 4 & $2^{\prime}$ & $77^{\prime}-42^{\prime}-53^{\prime}-88^{\prime}$ \\
\hline 262.5 & 4 & $2^{\prime}$ & $88^{\prime}-53^{\prime}-42^{\prime}-77^{\prime}$ \\
\hline 270.0 & 4 & $2^{\prime}$ & $77^{\prime}-42^{\prime}-53^{\prime}-88^{\prime}$ \\
\hline 277.5 & 4 & $2^{\prime}$ & $88^{\prime}-53^{\prime}-42^{\prime}-77^{\prime}$ \\
\hline 285.0 & 4 & $2^{\prime}$ & $77^{\prime}-42^{\prime}-53^{\prime}-88^{\prime}$ \\
\hline 292.5 & 4 & $2^{\prime}$ & $88^{\prime}-53^{\prime}-42^{\prime}-77^{\prime}$ \\
\hline 300.0 & 5 & $3^{\prime}$ & $77^{\prime}-64^{\prime}-53^{\prime}-88^{\prime}$ \\
\hline 307.5 & 5 & $3^{\prime}$ & $88^{\prime}-53^{\prime}-64^{\prime}-77^{\prime}$ \\
\hline 315.0 & 5 & $3^{\prime}$ & $77^{\prime}-64^{\prime}-53^{\prime}-88^{\prime}$ \\
\hline 322.5 & 5 & $3^{\prime}$ & $88^{\prime}-53^{\prime}-64^{\prime}-77^{\prime}$ \\
\hline 330.0 & 5 & $3^{\prime}$ & $77^{\prime}-64^{\prime}-53^{\prime}-88^{\prime}$ \\
\hline 337.5 & 5 & $3^{\prime}$ & $88^{\prime}-53^{\prime}-64^{\prime}-77^{\prime}$ \\
\hline 345.0 & 5 & $3^{\prime}$ & $77^{\prime}-64^{\prime}-53^{\prime}-88^{\prime}$ \\
\hline 352.5 & 5 & $3^{\prime \prime}$ & $88^{\prime}-53^{\prime}-64^{\prime}-77^{\prime}$ \\
\hline
\end{tabular}




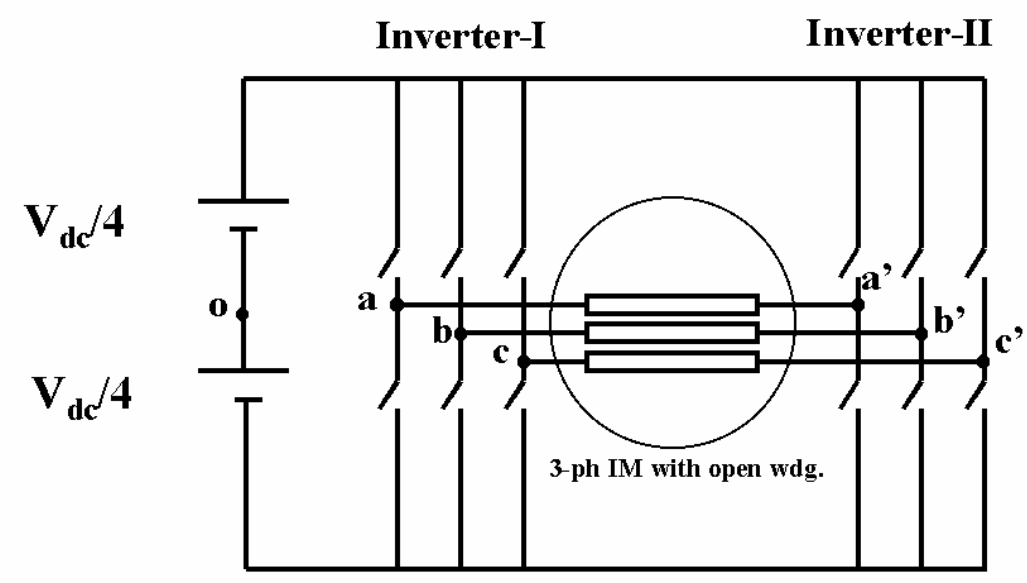

Fig. 1 Dual Inverter fed induction motor with open-end winding
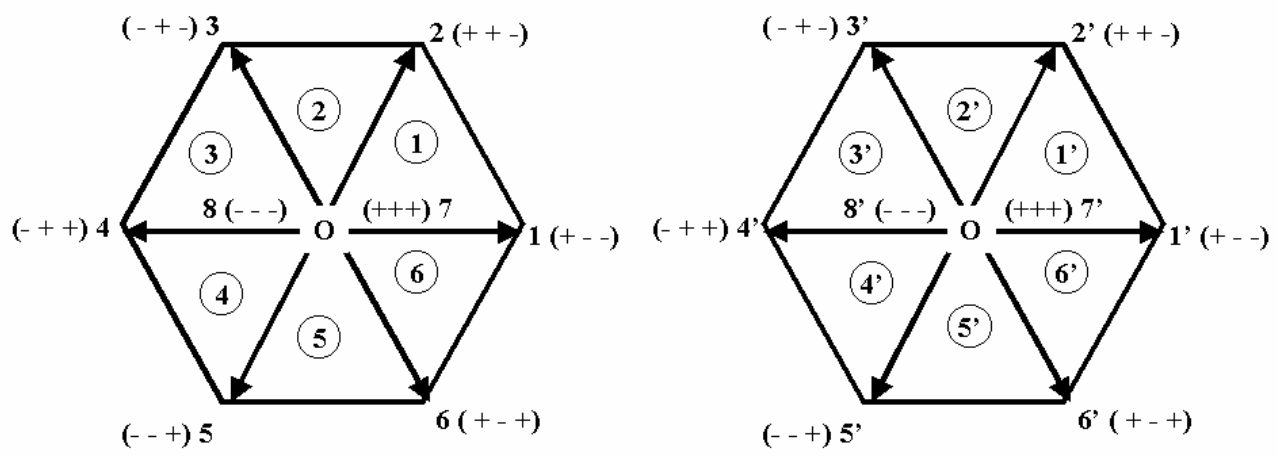

Fig.2 Space-vectors from inverter - 1 (Left) and inverter - 2 (Right)

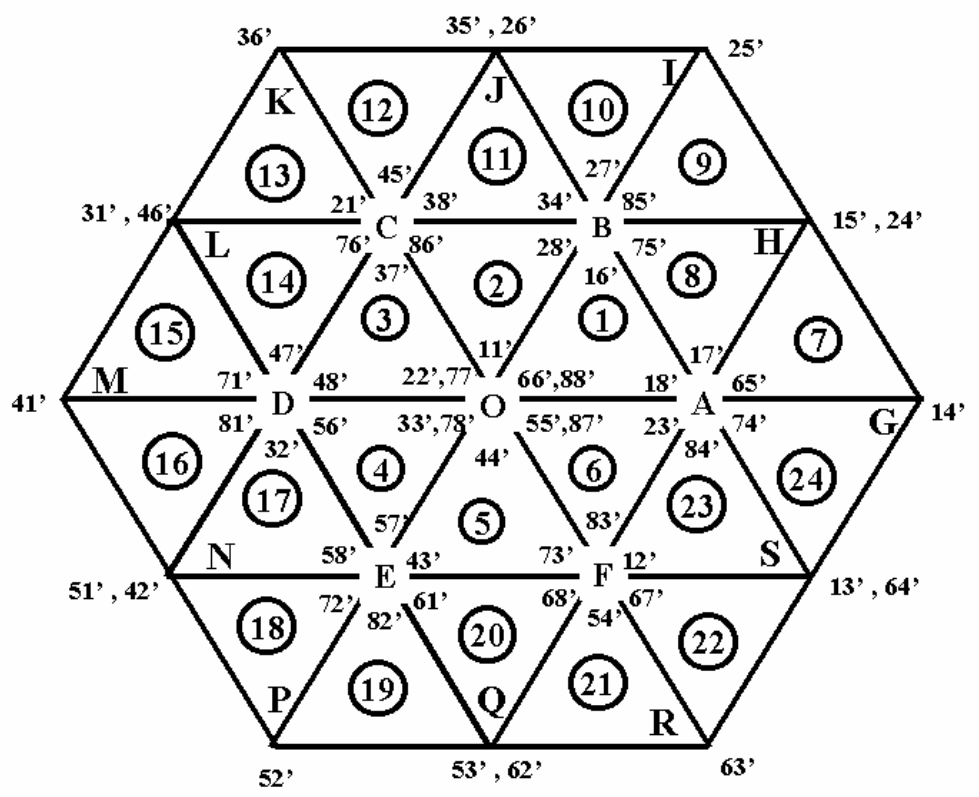

Fig.3 Space-vector combinations for the dual inverter scheme 


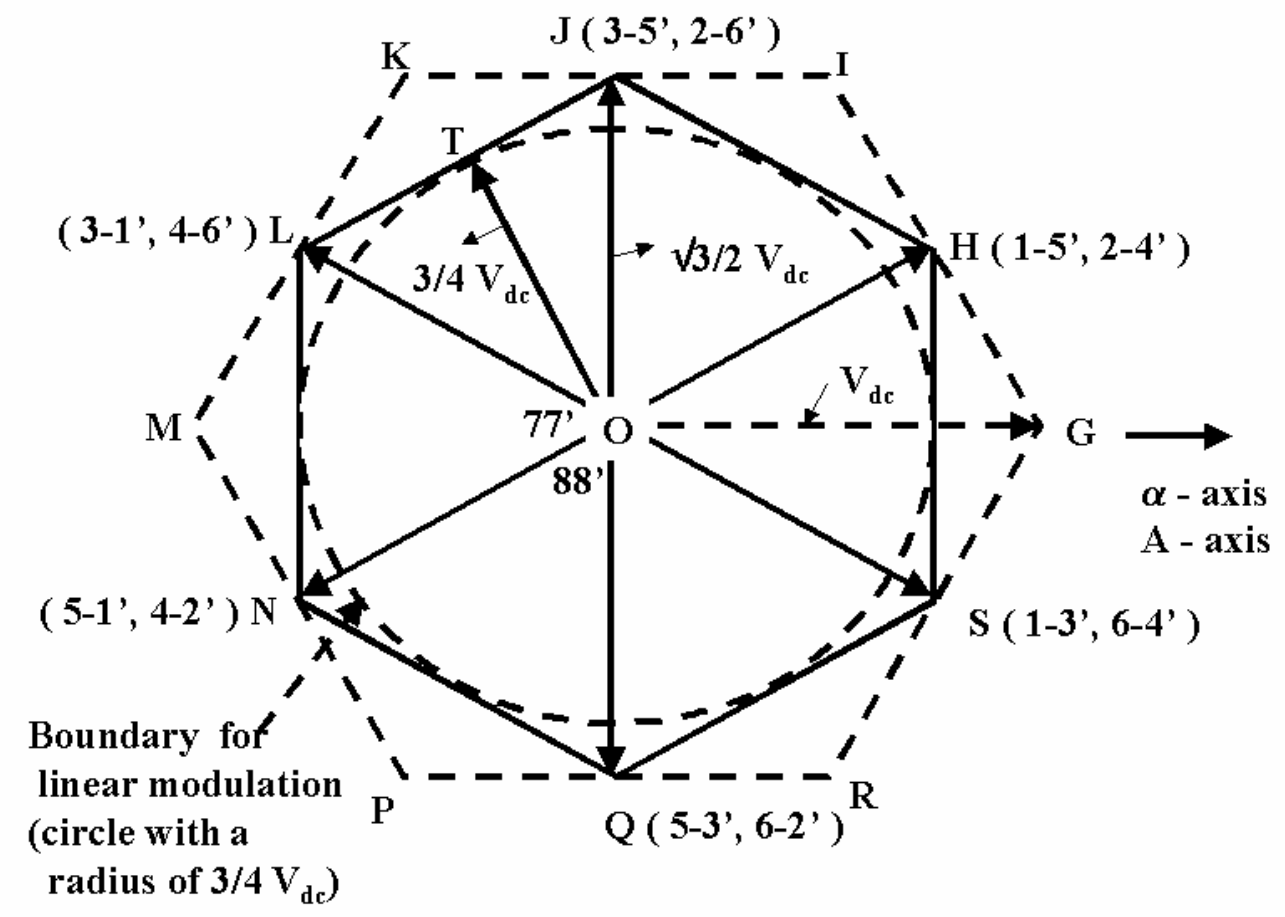

Fig.4 Space-vector combinations with a zero contribution towards the harmonics of the triplen order

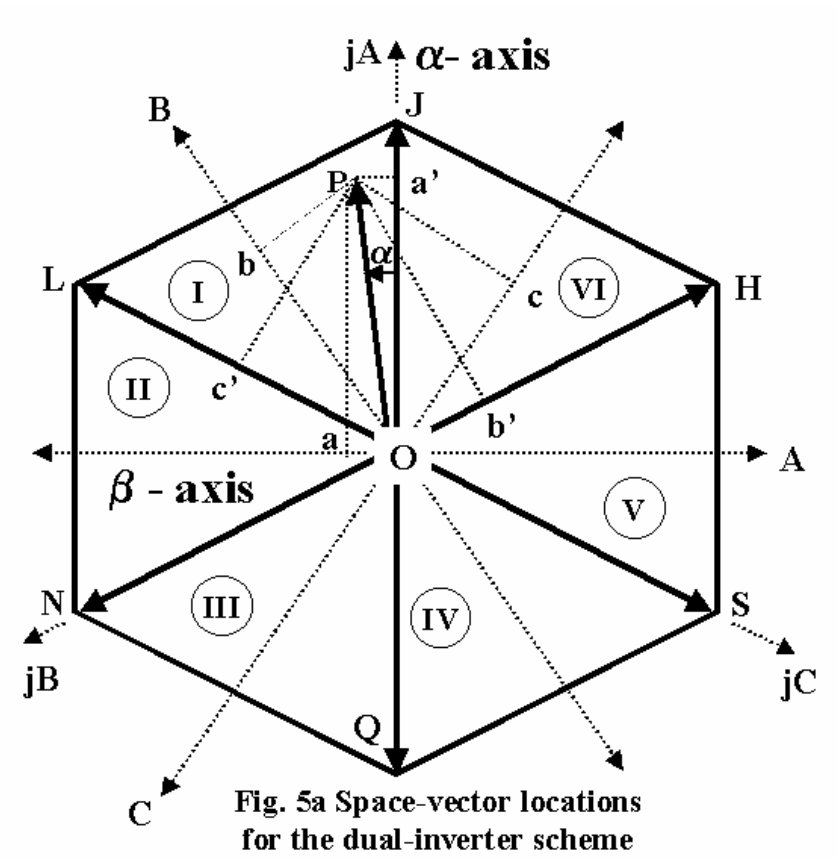

$$
\begin{aligned}
& \mathrm{OH}=\sqrt{3} / 2^{*} \mathrm{Vdc} \\
& \mathrm{OP}=|\mathbf{v s r}| ; \quad \angle \mathbf{P O J}=\boldsymbol{\alpha} \\
& \text { vasr }=2 / 3^{*} \mathrm{Oa} ; \text { vjasr }=2 / 3^{*} \mathrm{Oa} \text { ' } \\
& \text { vbsr }=2 / 3 * \mathrm{Ob} ; \mathrm{vjbsr}=2 / 3 * \mathrm{Ob} \text {, } \\
& \text { vbsr }=2 / 3^{*} \mathrm{Oc} ; \text { vjesr }=2 / 3^{*} \mathrm{Oc} \text { ' }
\end{aligned}
$$

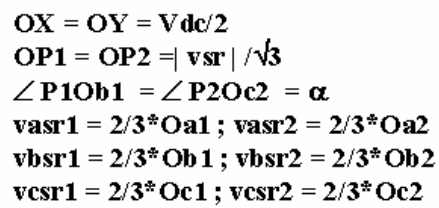

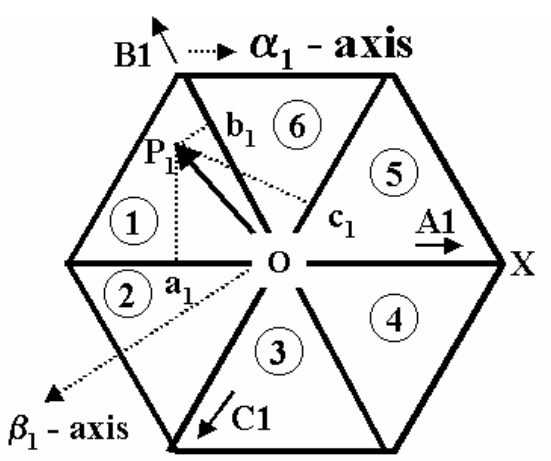

Fig. 5b Space-vector locations for inverter-1

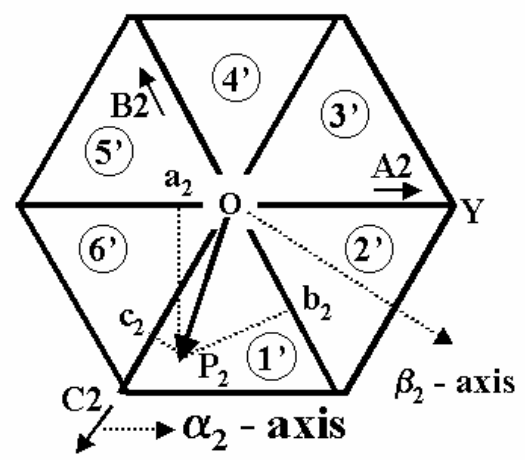

Fig. 5c Space-vector locations for inverter-2

Fig.5a - Space-vector locations and the instantaneous phase reference values $-\mathrm{v}_{\mathrm{asr}}, \mathrm{v}_{\mathrm{bsr}}, \mathrm{v}_{\mathrm{csr}}$ (along the regular axes - A,B and C) and vjasr, vjbsr, vjcsr (along the orthogonal axes - jA,jB and jC) for the dual-inverter scheme (Left).

Fig.5b and Fig.5c - Space-vector locations and the instantaneous phase reference values for individual inverters (Right). 


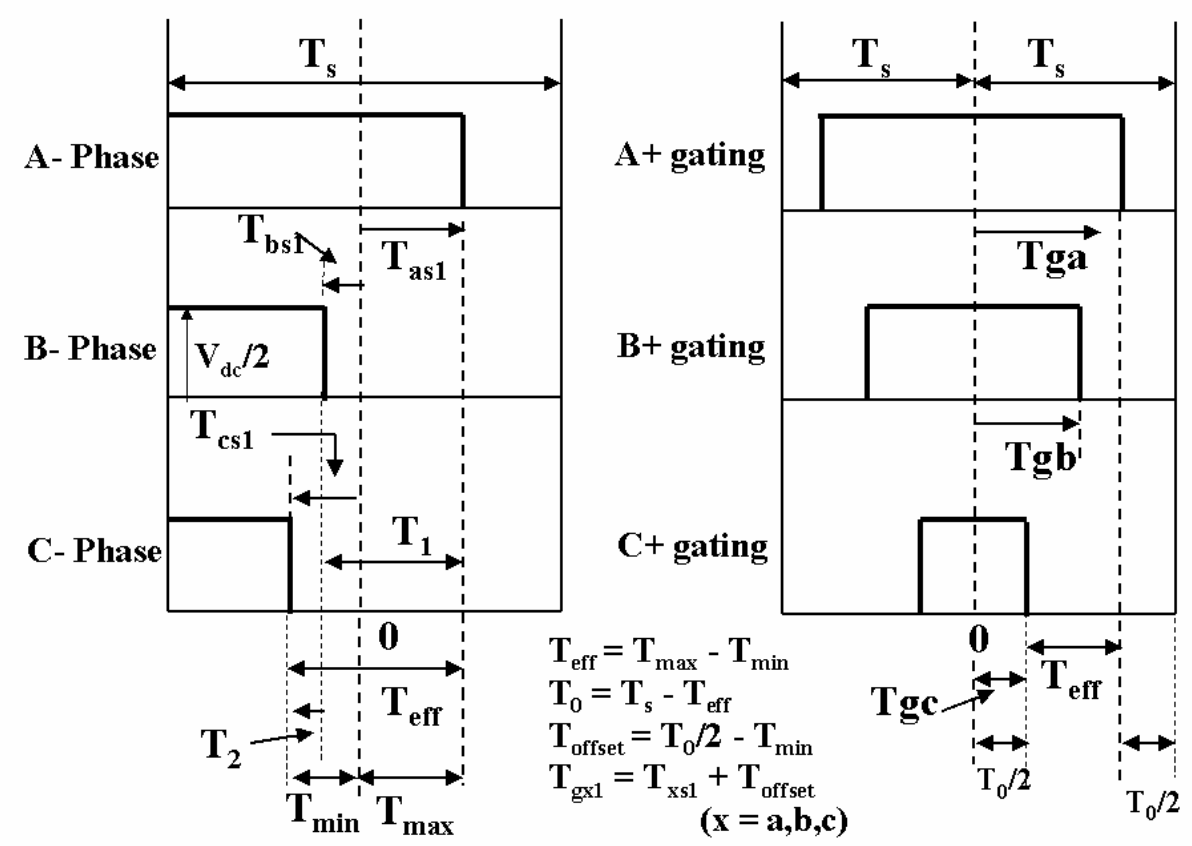

Fig.6 Generation of the gating signals for the inverter-1 when the tip of the reference voltage vector for inverter- $1\left(\mathbf{O P}_{\mathbf{1}}\right)$ is situated in the sector- 5 of inverter- 1 hexagon

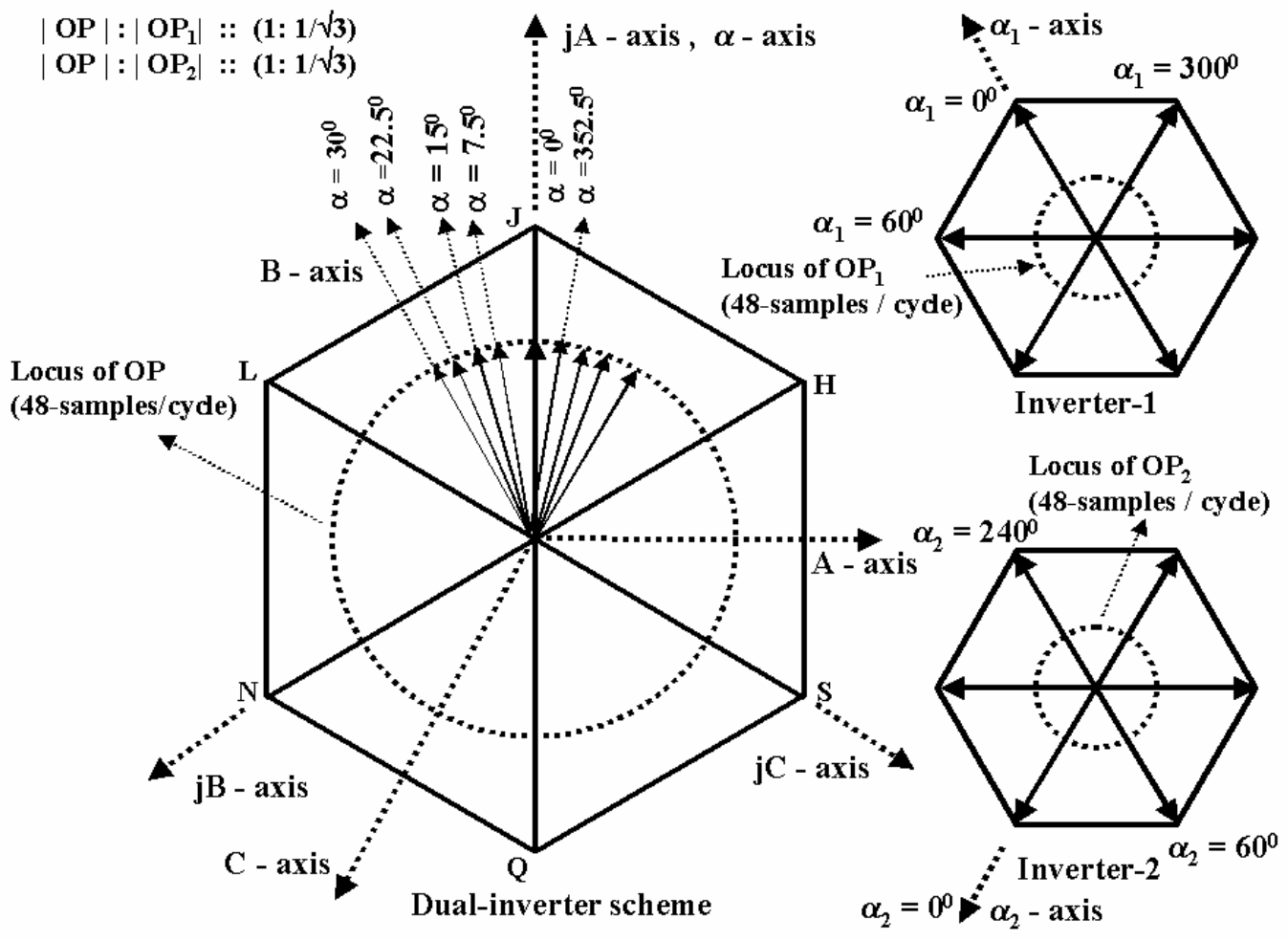

Fig.7 Sampling of the reference voltage space-vector $\mathbf{O P}$ (48-samples in one cycle of operation) 


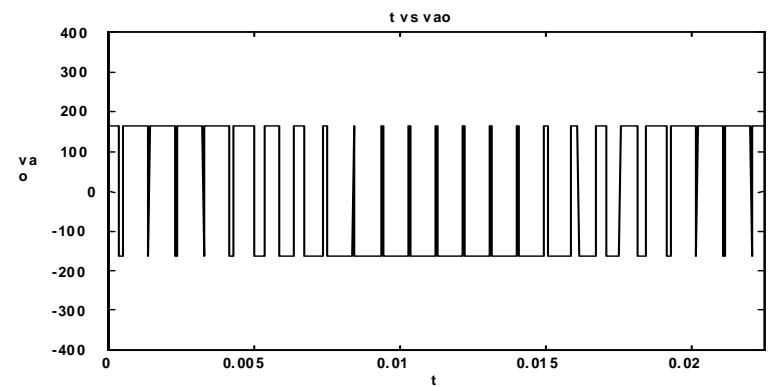

Fig.8a - The pole voltage $\mathrm{V}_{\mathrm{ao}}$ (Simulation result)

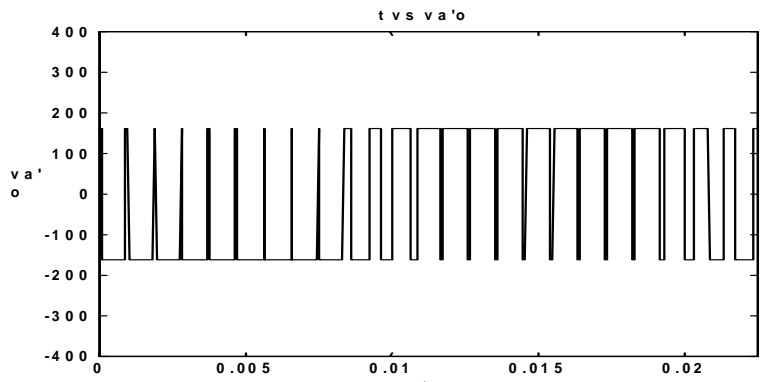

Fig.8b - The pole voltage $\mathrm{V}_{\mathrm{a}} \mathrm{o}$ (Simulation result)

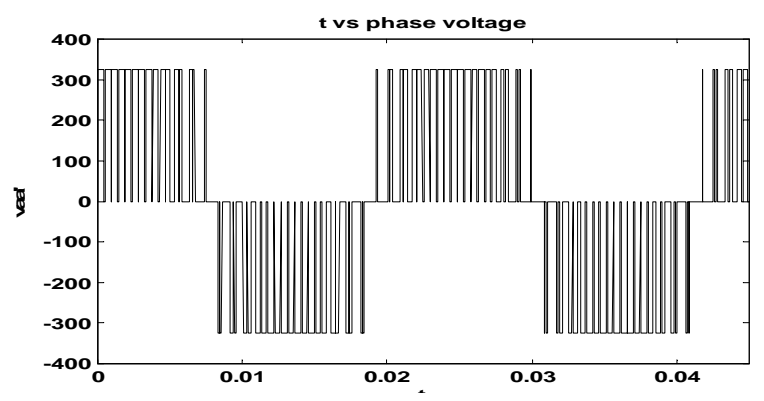

Fig.8c - The phase voltage $\mathrm{V}_{\mathrm{aa}}$ (Simulation result)

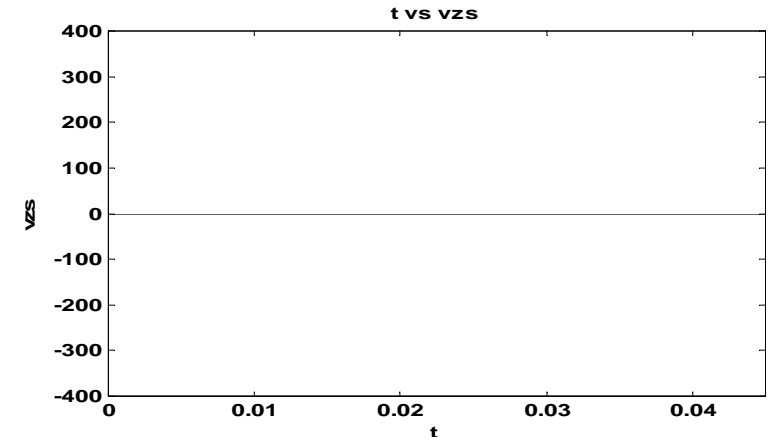

Fig.8d - The zero-sequence voltage of the Phase voltage $-\mathrm{V}_{\mathrm{aa}}$ (Simulation result)

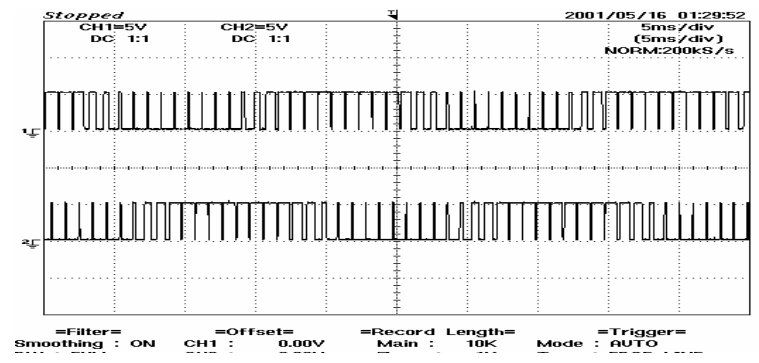

Fig. $8 \mathrm{e}$ - The pole voltages $\mathrm{V}_{\mathrm{ao}}$ and $\mathrm{V}_{\mathrm{a}} \mathrm{o}$ derived from the gating signals

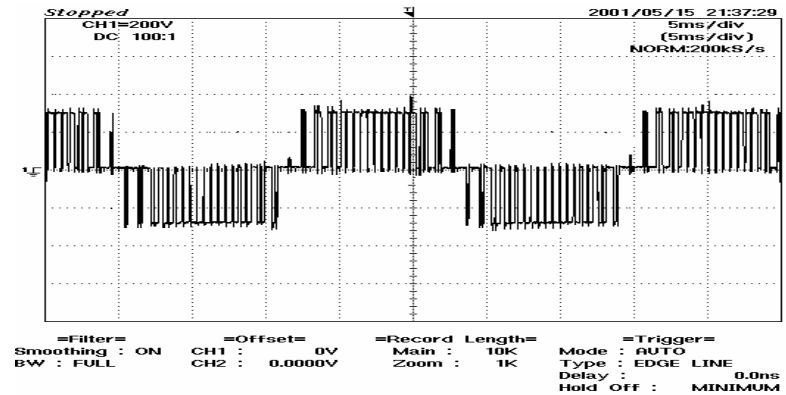

Fig.8f - The motor phase voltage $\mathrm{V}_{\mathrm{aa}}$ (Experimental result) Scale - X -axis: 5ms/div ; Y-axis: 200V/div

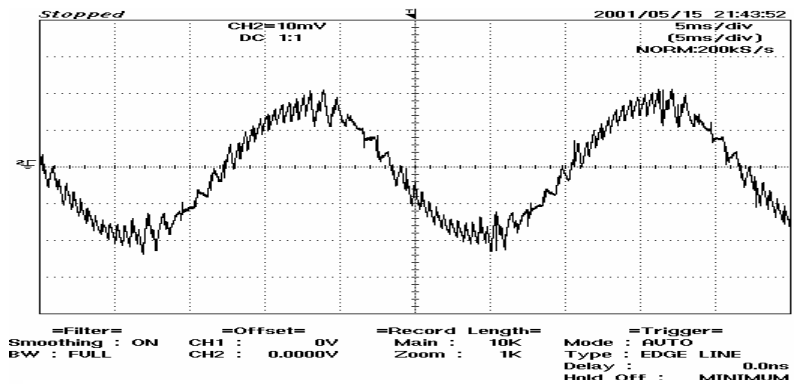

Fig.8g - The motor phase current at no-load (Experimental result)

Scale - X-axis: 5ms/div.; Y - axis: 0.5 Amps / div

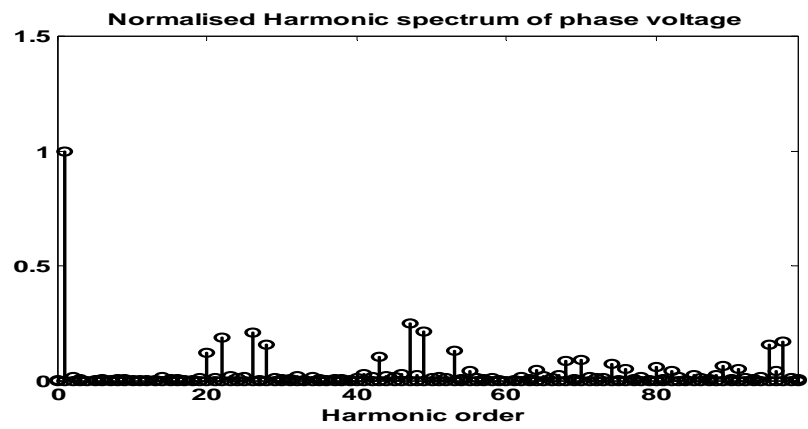

Fig.8h - The normalized harmonic spectrum of the phase voltage - $\mathrm{V}_{\mathrm{aa}}$ (Experimental result)

Fig.8 - The simulation (Left array) and the experimental results (Right array) for under-modulation when $|\mathbf{O P}|=0.65 \mathrm{~V}_{\mathrm{dc}}$ 


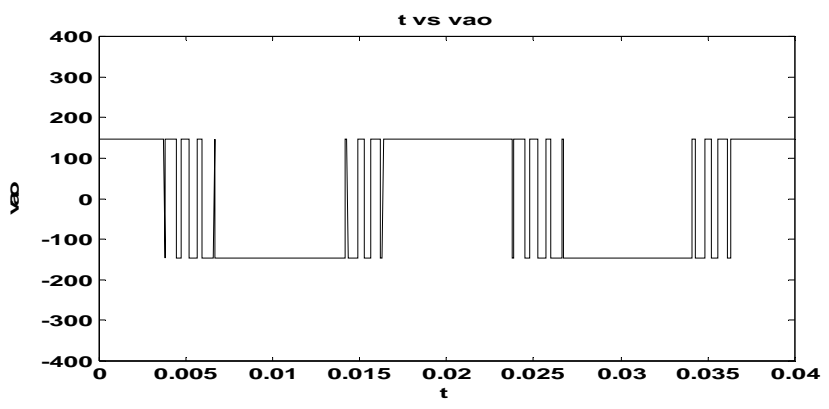

Fig.9a - The pole voltage $\mathrm{V}_{\mathrm{ao}}$ (Simulation result)

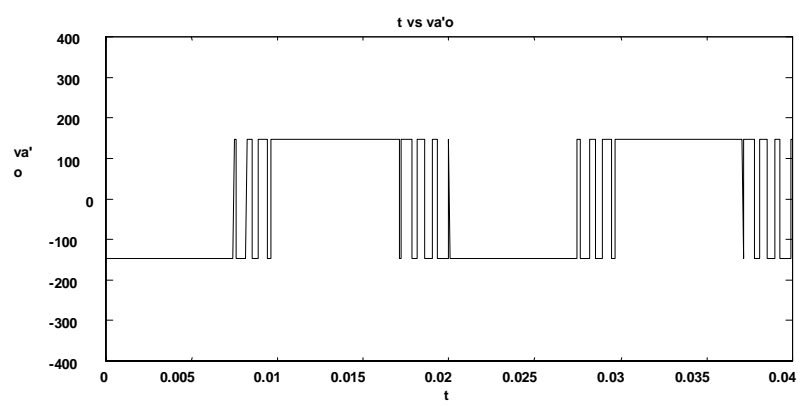

Fig.9b - The pole voltage $\mathrm{V}_{\mathrm{a}}$ (Simulation result)

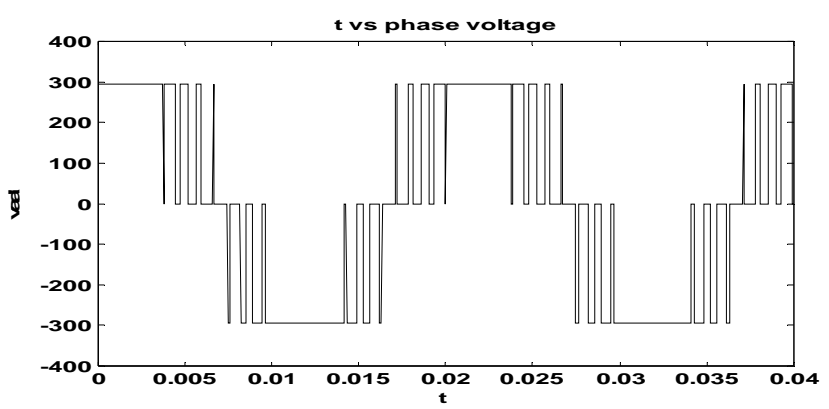

Fig.9c - The phase voltage $\mathrm{V}_{\mathrm{aa}}$ (Simulation result)

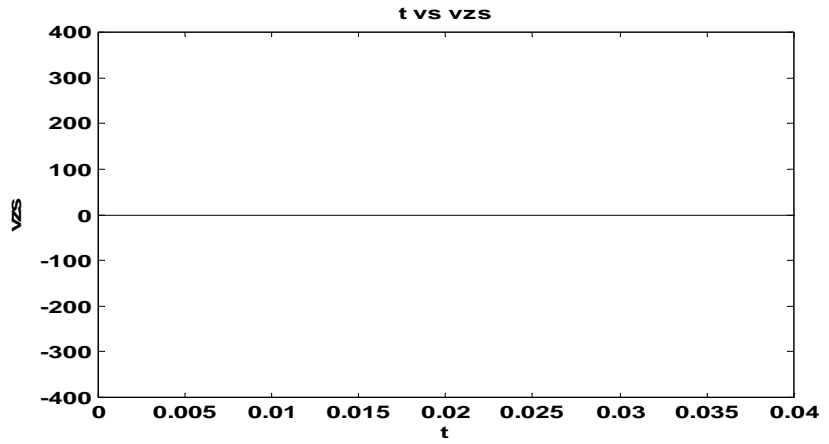

Fig.9d - The zero-sequence voltage of the Phase voltage $-\mathrm{V}_{\mathrm{aa}}$ (Simulation result)

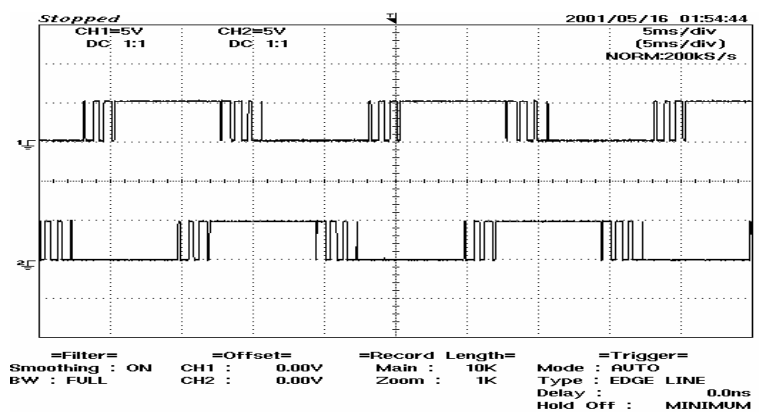

Fig. $9 \mathrm{e}$ - The pole voltages $\mathrm{V}_{\mathrm{a} o}$ and $\mathrm{V}_{\mathrm{a}} \mathrm{o}$ derived from the gating signals

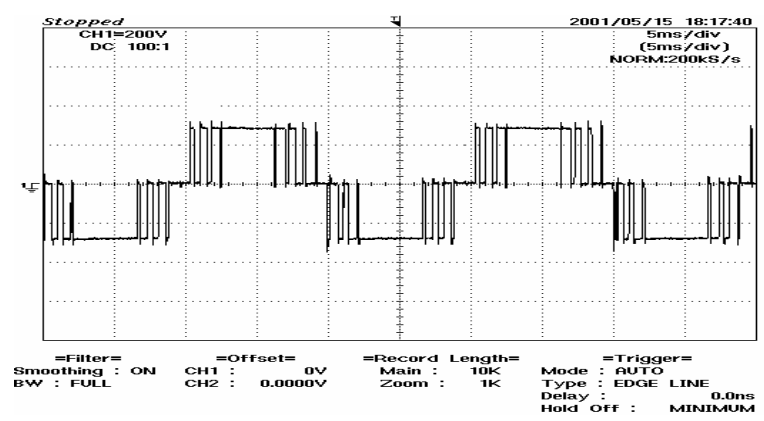

Fig.9f - The motor phase voltage $\mathrm{V}_{\mathrm{aa}}$ (Experimental result) Scale - X -axis: 5ms/div ; Y-axis: 200V/div

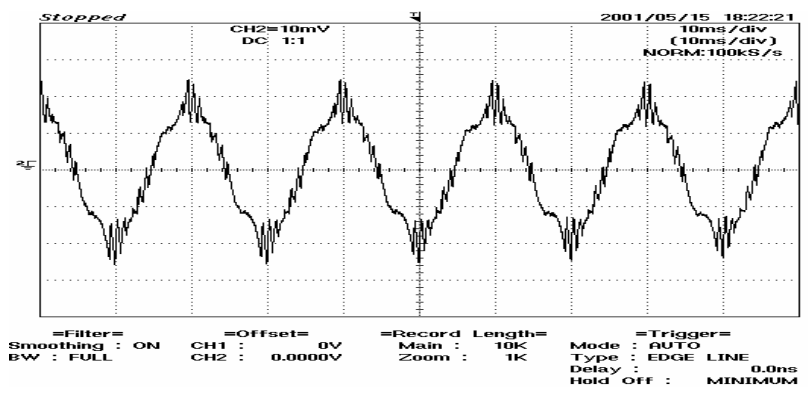

Fig.9g - The motor phase current at no-load Scale - X-axis : 5ms/div ; Y - axis : 0.5 Amps / div

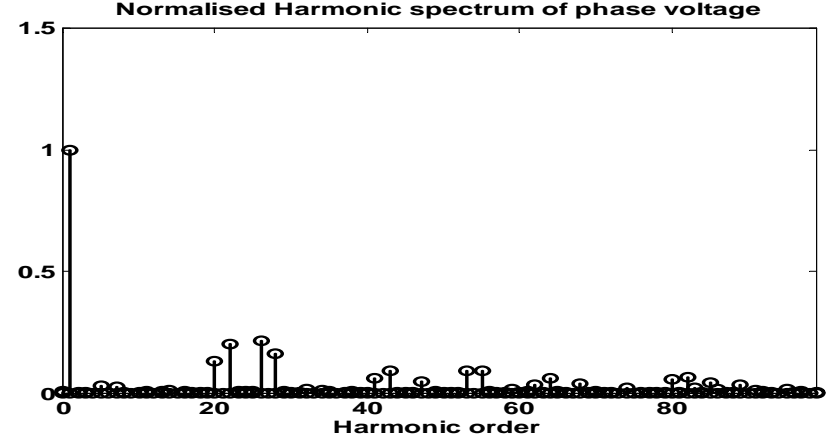

Fig.9h - The normalized harmonic spectrum of the phase voltage - $\mathrm{V}_{\mathrm{aa}}$ (Experimental result)

Fig.9 - The simulation (Left array) and the experimental results (Right array) for over-modulation (the tip of OP tracing the hexagon 'HJLNQS' 


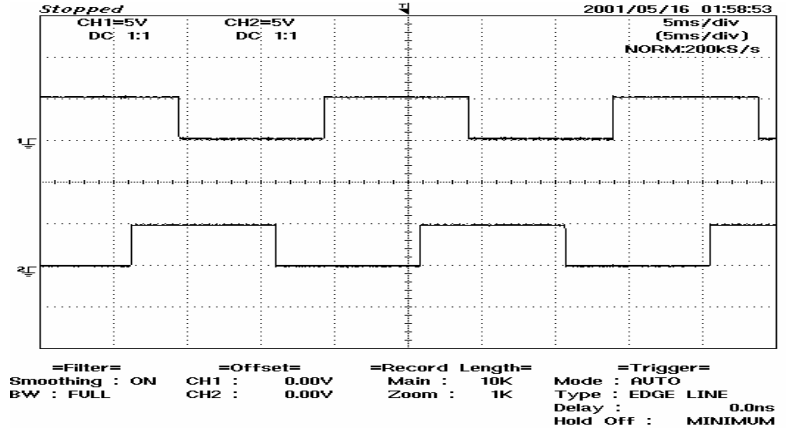

Fig. 10a - The pole voltages $\mathrm{V}_{\mathrm{ao}}$ and $\mathrm{V}_{\mathrm{a}} \mathrm{o}$ derived from the gating signals

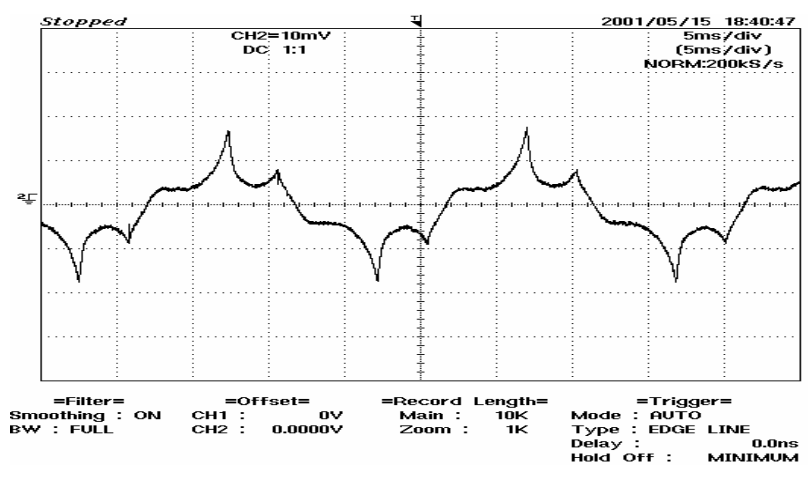

Fig.10c - The motor phase current at no-load Scale - X-axis : 5ms/div; Y - axis : 0.5 Amps / div

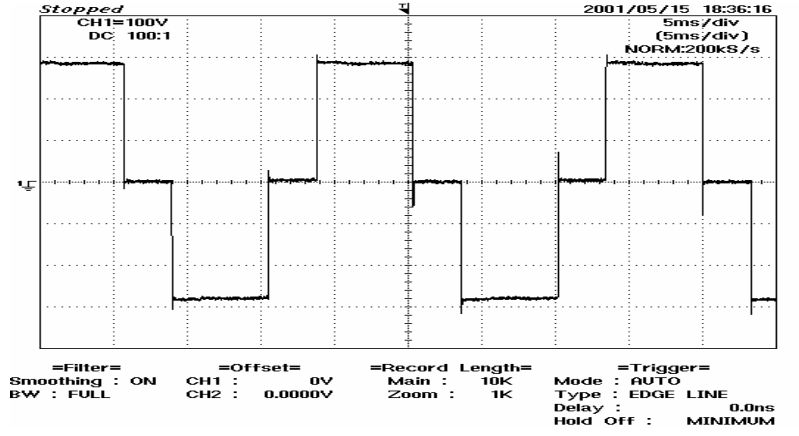

Fig.10b - The motor phase voltage $\mathrm{V}_{\text {aa' }}$ (Experimental result) Scale - X -axis: $5 \mathrm{~ms} / \mathrm{div}$; Y-axis: $100 \mathrm{~V} / \mathrm{div}$

Fig.10 - The simulation (Left array) and the experimental results (Right array) for six - step operation 